This item was submitted to Loughborough's Research Repository by the author.

Items in Figshare are protected by copyright, with all rights reserved, unless otherwise indicated.

\title{
A targeted near-infrared nanoprobe for deep-tissue penetration and imaging of prostate cancer
}

\section{PLEASE CITE THE PUBLISHED VERSION}

https://doi.org/10.1039/d0bm01970d

\section{PUBLISHER}

Royal Society of Chemistry (RSC)

\section{VERSION}

AM (Accepted Manuscript)

\section{PUBLISHER STATEMENT}

This paper was accepted for publication in the journal Biomaterials Science and the definitive published version is available at https://doi.org/10.1039/d0bm01970d

\section{LICENCE}

CC BY-NC-ND 4.0

\section{REPOSITORY RECORD}

Krishnan, Mena Asha, Kratika Yadav, Paul Roach, and Venkatesh Chelvam. 2021. "A Targeted Near-infrared Nanoprobe for Deep-tissue Penetration and Imaging of Prostate Cancer". Loughborough University. https://hdl.handle.net/2134/14236772.v1. 


\title{
Targeted Near-infrared Nanoprobes for Early Detection and Surgical Guidance of Prostate Cancer
}

\author{
Mena Asha Krishnan, ${ }^{\text {a }}$ Paul Roach, ${ }^{\text {c,* }}$ Venkatesh Chelvam, ${ }^{\text {a, }}{ }^{*}$
}

a) Discipline of Biosciences and Biomedical Engineering, Indian Institute of Technology Indore, Indore 453 552, India.

b) Discipline of Chemistry, Indian Institute of Technology Indore, Indore 453 552, India.

c) Department of Chemistry, University of Loughborough, Leicestershire LE11 3TU, United Kingdom

*Corresponding Authors

Dr. Venkatesh Chelvam

Email ID: cvenkat@iiti.ac.in

Discipline of Biosciences and Biomedical Engineering, Discipline of Chemistry, Indian Institute of Technology Indore, Indore 453 552, India.

Dr. Paul Roach

Email ID: p.roach@lboro.ac.uk

Department of Chemistry, University of Loughborough, Leicestershire LE11 3TU, United Kingdom 


\begin{abstract}
Fluorescent guided surgery (FGS) has been highlighted as a potential to increase precision of diseased tissue whilst minimising the removal of surrounding healthy tissue, particularly relevant for increasingly prevalent prostate cancer $(\mathrm{PCa})$. There remain challenges in the design of imaging probes presenting high selectivity for tumour tissue, clear visualization and minimal toxicity. Here we report the design and development of a novel NIR-nanoprobe and evaluate its potential in penetration inside PCa tumour tissues. Prostate-specific membrane antigen (PSMA) receptor-targeted near infrared emitting quantum dots (PSMA-NIR-QDot) are demonstrated as deep tissue imaging agents for intraoperative navigation during surgery and improving detection specificity for PCa. Probes were designed and synthesized by conjugating functionalized amino-PEG QDots through a heterobifunctional linker to a DUPA targeted polypeptide construct. Nanoprobes were evaluated in vitro in $\mathrm{PSMA}^{+} \mathrm{PCa}$ cell lines for specificity and affinity determined by flow cytometric analysis. The penetration efficacy was tested further on large PCa 3D tumour spheroids (dia $\sim 1.2 \mathrm{~mm}$, width $\sim 250 \mu \mathrm{m}$ ) by deep tissue multiphoton imaging. The PSMA-NIR-Qdot was found to be an efficient deep tissue penetrating intra-operative guided surgical tool with high affinity $\left(K_{D}=15 \mathrm{nM}\right)$ and penetrative capacity. The results have been demonstrated in vitro in $2 \mathrm{D}$ and $3 \mathrm{D}$ tissue models, mimicking cancer lesions in vivo. The presented deep-tissue imaging NIR nanoprobes target prostatic lesions that (i) bind to $\mathrm{PSMA}^{+}$tumour with sub-nanomolar affinity and high specificity, (ii) show excellent safety profile in primary cell lines in vitro, and (iii) show high penetrative capacity in 3D prostate tumour model $(\sim 250 \mu \mathrm{m}$ tissue depth). These probes may potentially offer vastly improved surgical accuracy for diseased tissue removal.
\end{abstract}

Keywords: PSMA, fluorescence guided surgery, targeted near-infrared quantum dot, penetration, multi-photon imaging, 3D tumour model.

\title{
Introduction
}

Prostate cancer (PCa) is currently the most common, debilitating, neoplastic disorder affecting men in the United States and Western Europe, with mortality rates continuing to increase annually. ${ }^{1}$ Screening using controversial Prostate Specific Antigen (PSA) serum levels and digital rectal examination (DRE) tests have improved curability, but overdiagnosis of clinically insignificant cancers results in unnecessary treatment and associated risks. ${ }^{2}$ Several new imaging modalities have been trialled, including ultrasound-based imaging, multiparametric (mp)-MRI, mp MRI-US fusion imaging and PET scanning, being selected based on biological behaviour of underlying tumour. ${ }^{3}$ However, sub-optimal accuracy in extra-prostatic tumour detection, resulting in biochemical relapse, has highlighted a need for the development of novel imaging probes with higher sensitivity of target tissue. ${ }^{4}$ 
Apart from early detection of cancerous lesions and clinical staging of $\mathrm{PCa},{ }^{5}$ radical prostatectomy (RP) has also significantly improved mortality rates when compared with nonsurgical therapeutic strategies like radiation and androgen-deprivation therapy. ${ }^{6}$ Considered the gold standard for treatment, RP halves the risk in patients aged 65-80 years with localized low-or intermediate-stage tumour (Gleason score $<7) .^{7}$ However, the ability to resect tumours currently lies on accuracy and reliability of visualization and/or the ability to palpate it. Tumour visualization is limited by low contrast between diseased and neighbouring healthy tissue, causing many micro-malignancies to be overlooked, else more commonly, drastically more healthy tissue being unnecessarily being removed causing further complications. Moreover, determination of tumour margin is currently achieved blindly, followed by frozen section pathologic analysis. ${ }^{8}$ Studies show almost $30 \%-40 \%$ of patients fail primary treatment and the rising PSA test levels herald the onset of biochemical recurrence. ${ }^{9}$ Hence, PCa management strategies need to focus on development of sensitive imaging techniques to effectively locate micro-lesions for diagnosis, as well as guide surgical interventions for complete removal of during surgery. One such strategy is fluorescenceguided surgery (FGS) augmented with molecular imaging. ${ }^{10}$ Molecular imaging is defined by a chemical probe, targeting a biomarker expressed on cancer tissues thereby providing realtime, intra-operative distinction of malignant and adjacent normal tissue and decreasing positive margins after surgery. ${ }^{11}$

Prostate-specific membrane antigen (PSMA) is a type II transmembrane glycoprotein and makes an excellent target for molecular imaging of $\mathrm{PCa}$, due to the following reasons: (1) it is significantly overexpressed (100-1,000 fold) on nearly all PCa cells, ${ }^{12}$ (2) its expression is further increased in advanced stages and metastatic-castration resistant $\mathrm{PCa}^{13}$ (3) ligands binding to the active centre of the extracellular domain are internalized with subsequent endosomal recycling leading to deposition. This results in enhanced tumour uptake, retention, and subsequent high image quality for diagnostic procedures and a high local dose for therapeutic applications. ${ }^{14,15}$ Small-molecule PSMA ligands are promising clinical candidates as they are usually cleared rapidly from circulation, leading to low background early after injection. 3-(1,3-Dicarboxypropyl)-ureido]pentanedioic acid (DUPA) belongs to a class of glutamate-ureido compounds having a high binding affinity with PSMA $\left(\mathrm{Ki}=8 \mathrm{nM}, \mathrm{IC}_{50}=\right.$ $47 \mathrm{nM}) .{ }^{16-18}$ PSMA, on binding with DUPA, undergoes endocytosis through clathrin-coated pits, unloads the ligand, and then recycles rapidly to the cell surface, making DUPA an ideal targeting ligand for consideration. ${ }^{19}$

A plethora of PSMA-targeted low-molecular weight, high affinity probes have been demonstrated over the past decade for fast tumour uptake and rapid excretion. ${ }^{20}{ }^{99 \mathrm{~m}} \mathrm{Tc}-$ labelled PSMA I\&S (for imaging and assisted surgery) and $\left[{ }^{111}\right.$ In]PSMA I\&T for radio-guided surgery were modified and optimized as a PSMA-targeted intra-operative probe. ${ }^{21,22}{ }^{123}$ I-labelled MIP 1072 was evaluated as a diagnostic agent in preclinical and first human studies. ${ }^{23}$ However, transportation logistics, convenience in handling, along with safety and limited production of radioisotopes within few countries curbs future widespread clinical use. ${ }^{24}$ Alternatively, PSMA-targeted near infrared fluorescence (NIRF) imaging is an attractive strategy for visual guidance using PCa surgery. ${ }^{25}$ GPI-78 was the first synthesized 
small molecule PSMA-NIR conjugate with enhanced affinity. ${ }^{26}$ PSMA-1 ligand labelled with IRDye800 and Cy5.5 were shown to selectively target orthotopic PSMA-positive PC3-PIP tumour. ${ }^{27}$ PSMA-specific probes combining DUPA inhibitor with NIR dyes such as S0456, Alexafluor 647, Dylight 680 and IRDye800CW have also been developed. ${ }^{28}$ These NIR fluorophores are however, plagued with photon absorption and scattering within a few tissue layers, drastically limiting penetration depth and therefore restricting their use for deep tssue imaging. ${ }^{29}$ Lipophilicity of many NIR fluorophores also significantly hampers pharmacokinetics and tumour targeting properties of the homing ligand. ${ }^{30}$

In contrast, Quantum Dots (QDots/QDs) have unique photochemical properties which make them powerful tools for fluorescence-guided surgical imaging. Photostability, broad excitation spectrum, narrow Gaussian emission at wavelengths controllable by material size along with multiphoton imaging enables deep imaging of patient tissues. ${ }^{31}$ For biological applications, robust water-soluble, QDs are required. Hence, a synthetic strategy enabling surface functionalization of QDs with water-soluble DUPA ligand via a peptidic spacer is adopted for effective deep tissue NIR, PSMA targeted-imaging.

Based on these considerations, we report the design and use of a PSMA targeting deep tissue imaging nano-probe constructed of three main components: (a) DUPA (2-[3-(1, 3-dicarboxy propyl)ureido] pentanedioic acid), a high affinity PSMA targeting ligand, (b) oligopeptide spacer linking homing moiety to fluorescent tag and (c) NIR-emitting CdTe/CdS QD fluorescent probe. We describe the synthesis and characterization, optical properties and preclinical evaluation via in vitro PCa cell lines. The effective penetration and distribution profile in a 3D PCa spheroid model is also demonstrated. Finally, preclinical evidence of PSMA-NIR-QDots remarkable safety profile in primary renal and macrophage cell lines is provided.

\section{Materials and Methods}

\section{Chemical synthesis}

\section{General methods and materials}

H-Cys(Trt)-2-ClTrt resin, Fmoc-amino acids, coupling reagents and solvents used in the solid phase peptide synthesis (SPPS) as well as in the chemical synthesis were purchased from Iris Biotech $\mathrm{GmbH}$, Sigma Aldrich, Merck and Spectrochem. Dry solvents were prepared by using appropriate drying agents and standard procedures. Moisture and oxygen sensitive reactions were carried out under nitrogen atmosphere. Thin layer chromatography (TLC) was performed on silica gel glass TLC plates $\left(60 \mathrm{~F}_{254}\right)$ and visualized under UV light to monitor the progress of the reaction. DUPA ligand was purified by column chromatography using 100-200 mesh silica-gel as the stationary phase. Distilled hexane and ethyl acetate were used as eluents in the column chromatography. Peptide synthesis was performed manually by using peptide vessels (Chemglass) and standard peptide coupling procedures. ${ }^{1} \mathrm{H}$ and ${ }^{13} \mathrm{C}$ NMR spectra were recorded using Bruker AV $400 \mathrm{MHz}$ NMR 
spectrometer with TMS as an internal standard. ${ }^{1} \mathrm{H}$ NMR signals were reported in ppm with reference to residual $\mathrm{CHCl}_{3}(7.25 \mathrm{ppm})$ and multiplicity was reported as $\mathrm{s}=$ singlet, $\mathrm{d}=$ doublet, $\mathrm{t}=$ triplet, $\mathrm{q}=$ quartet, $\mathrm{m}=$ multiplet or unresolved, and brs = broad singlet, with coupling constants in $\mathrm{Hz}$. $\mathrm{CDCl}_{3}$ was used as the solvent for recording NMR spectra. Mass spectra were recorded on Bruker micro TOF-Q II instrument using positive or negative mode electrospray ionization methods. The purity of DUPA-SH linker 7 was analyzed using Dionex HPLC-Ultimate 3000 Analytical HPLC instrument. The peptide conjugate 7 was purified using RP-PFP column (XSelect CSH Prep Fluorophenyl $5 \mu \mathrm{m}$ OBD, $19 \mathrm{~mm} \times 150$ $\mathrm{mm}$ ) in Buchi Reveleris High Performance Preparative Chromatography instrument.

\section{Chemical synthesis of targeting ligand}

Triphosgene $(0.050 \mathrm{~g}, 0.169 \mathrm{mmol})$ was dissolved in $3 \mathrm{~mL}$ dry DCM and the solution was stirred at $-50{ }^{\circ} \mathrm{C}$ under inert atmosphere. Bis(tert-butyl)-L-glutamate. $\mathrm{HCl}(\mathbf{1}, 0.150 \mathrm{~g}$, $0.507 \mathrm{mmol}$ ) dissolved in $2 \mathrm{~mL}$ of dry DCM was added to triphosgene solution at $-50{ }^{\circ} \mathrm{C}$ and triethylamine $(0.5657 \mathrm{~mL}, 4.056 \mathrm{mmol})$ was added dropwise to the reaction mixture. The reaction mixture was stirred for $1.5 \mathrm{~h}$ at $-50{ }^{\circ} \mathrm{C}$ and stirred for another $1.5 \mathrm{~h}$ at room temperature for the generation of isocyanate intermediate 2. Thereafter, a solution of L-glutamic- $\gamma$-benzyl- $\alpha$-tert-butyl. $\mathrm{HCl}(0.159 \mathrm{~g}, 0.507 \mathrm{mmol})$ and triethylamine $(0.14 \mathrm{~mL}$, $1.014 \mathrm{mmol}$ ) in DCM was added to the reaction mixture. The progress of the reaction was monitored through TLC using ethyl acetate and hexane (1:3) mixture as eluent. The reaction mixture was stirred overnight at room temperature. After reaction completion the mixture was concentrated under reduced pressure, diluted with ethyl acetate, washed with water and brine. The organic layer was dried over anhydrous $\mathrm{Na}_{2} \mathrm{SO}_{4}$, filtered and evaporated under reduced pressure to afford crude reaction mixture which was purified by column chromatography over 100-200 mesh silica gel using 25\% ethyl acetate and hexane as eluent. The purified compound was obtained as colorless viscous liquid; Yield 85\% (249 mg), the purified benzyl tris(tert-butoxy) protected DUPA precursor 3. Detailed synthetic scheme is shown in supporting information (S1).

(S)-5-Benzyl 1-tert-butyl 2-(3-((S)-1,5-di-tert-butoxy-1,5-dioxopentan-2yl)ureido)pentanedioate (3): Yellowish gummy liquid (yield $=85 \%, 249 \mathrm{mg}$ ), $R_{\mathrm{f}}=0.29$ $($ EtOAc/hexane $=1: 3) ;{ }^{1} \mathrm{H}$ NMR $\left(400 \mathrm{MHz} \mathrm{CDCl}_{3}\right) \delta 7.33(\mathrm{~m}, 5 \mathrm{H}), 5.10-5.04(\mathrm{~m}, 4 \mathrm{H})$, 4.38-4.28 (m, 2H), 2.51-2.37 (m, 2H), 2.32-2.23 (m, 2H), 2.20-2.12 (m, 1H), 2.09-2.00 (m, $1 \mathrm{H}), 1.96-1.81(\mathrm{~m}, 2 \mathrm{H}), 1.44(\mathrm{~s}, 9 \mathrm{H}), 1.43(\mathrm{~s}, 9 \mathrm{H}), 1.41(\mathrm{~s}, 9 \mathrm{H}) ;{ }^{13} \mathrm{C} \mathrm{NMR}\left(100 \mathrm{MHz}, \mathrm{CDCl}_{3}\right)$ $\delta 172.9,172.5,172.0,171.9,156.8,135.8,128.5,128.2,82.1,82.0,80.5,66.4,53.1,53.0$, 31.5, 30.3, 28.4, 28.3, 28.1, 28.0; HRMS (ESI) $m / z$ : $[\mathrm{M}+\mathrm{Na}]^{+}$calculated for $\mathrm{C}_{30} \mathrm{H}_{46} \mathrm{~N}_{2} \mathrm{O} 9$, 601.3096; found, 601.3092.

Procedure for debenzylation of benzyl tris(tert-butoxy)-protected DUPA precursor 3 to give (S)-5-(tert-butoxy)-4-(3-((S)-1,5-di-tert-butoxy-1,5-dioxopentan-2-yl)ureido)-5oxopentanoic acid (4):

To a solution of benzyl tris(tert-butoxy) protected DUPA precursor $3(0.250 \mathrm{~g}$, $0.434 \mathrm{mmol})$ in dichloromethane $(10 \mathrm{~mL}), 10 \mathrm{~mol} \% \mathrm{Pd} / \mathrm{C}(40 \mathrm{mg})$ was added. The reaction mixture was hydrogenated under an atmosphere of $\mathrm{H}_{2}$ gas (1 atm) for $24 \mathrm{~h}$ at room 
temperature. After completion of the reaction, $\mathrm{Pd} / \mathrm{C}$ was filtered off through a celite bed and washed with DCM $(3 \times 5 \mathrm{~mL})$. The solvent was evaporated under reduced pressure and the crude product was purified through column chromatography (hexane/ethyl acetate $=50: 50$ ) to afford the tris(tert-butoxy)-protected DUPA precursor $\mathbf{4}$ which was further used for peptide coupling reaction in the solid-phase peptide synthesis.

(S)-5-(tert-Butoxy)-4-(3-((S)-1,5-di-tert-butoxy-1,5-dioxopentan-2-yl)ureido)-5oxopentanoic acid (4):

Colourless viscous liquid solidified on standing (yield $=80 \%, 169 \mathrm{mg}$ ), $R_{\mathrm{f}}=0.48$ $($ EtOAc/hexane $=1: 1) ;{ }^{1} \mathrm{H}$ NMR $\left(400 \mathrm{MHz}, \mathrm{CDCl}_{3}\right) \delta 5.01(\mathrm{~d}, J=7.76 \mathrm{~Hz}, 2 \mathrm{H}), 4.32$ (ddd, $J$ $=5.0,5.26,7.76 \mathrm{~Hz}, 2 \mathrm{H}), 2.37-2.21(\mathrm{~m}, 4 \mathrm{H}), 2$.

2H), 1.89-1.80 (m, 2H), 1.45 (s, 9H), $\left.1.42(\mathrm{~s}, 18 \mathrm{H}) ;{ }^{13} \mathrm{C} \mathrm{NMR} \mathrm{(100} \mathrm{MHz,} \mathrm{CDCl}_{3}\right) \delta 176.1$, $173.1,172.5,171.9,157.8,82.5,82.1,80.6,53.3,53.0,31.5,30.3,28.4,28.1,28.0,27.9$, 27.8; HRMS (ESI) $m / z$ : $[\mathrm{M}+\mathrm{Na}]^{+}$calcd for $\mathrm{C}_{23} \mathrm{H}_{40} \mathrm{~N}_{2} \mathrm{O} 9,511.2626$; found, 511.2640.

\section{General procedure for solid-phase synthesis Resin swelling}

All the resins used in solid-phase peptide synthesis were swelled initially with $5 \mathrm{~mL}$ of DCM for 30 minutes by bubbling nitrogen and after draining DCM, the resin is swelled once again with $5 \mathrm{~mL}$ DMF thrice for 15 minutes each.

\section{General procedure for the Kaiser test}

A sample of resin beads were taken in a test-tube and 2 drops of each of ninhydrin, phenol and $0.1 \%$ potassium cyanide solution were added to the test-tube and heated for 2 minutes at $110{ }^{\circ} \mathrm{C}$ in a sand bath. The presence of free amine groups was confirmed by the appearance of dark blue colored resin beads in the test tube. The test was performed after coupling of each amino acid by the aforementioned procedure.

\section{General procedure for NHFmoc deprotection}

The Fmoc-amino group in the growing peptide chain was deprotected in each step using $20 \%$ piperidine in DMF $(10 \mathrm{~mL})$ by bubbling nitrogen for 10 minutes through the swelled resin beads. The procedure was repeated thrice $(1 \times 4 \mathrm{~mL} ; 2 \times 3 \mathrm{~mL})$ to ensure complete deprotection of Fmoc protecting group.

\section{General procedure for peptide cleavage from resin beads}

A mixture of $9.25 \mathrm{~mL}$ trifluoroacetic acid (TFA), $0.25 \mathrm{~mL}$ triisopropylsilane (TIPS), $0.25 \mathrm{~mL}$ EDT and $0.25 \mathrm{~mL} \mathrm{H} \mathrm{H}_{2} \mathrm{O}$ were prepared and $5 \mathrm{~mL}$ of this cocktail solution was added to resin beads and nitrogen was bubbled through the solution for 30 minutes. The same procedure was repeated twice using $2.5 \mathrm{~mL}$ of cocktail solution. The collected mother liquor from cleavage was evaporated under reduced pressure and the concentrated viscous liquid was precipitated in ice cold diethyl ether. The precipitated product was dried under nitrogen atmosphere and utilized for further studies. 
H-Cys(Trt)-2-ClTrt resin (0.050 g, $0.031 \mathrm{mmol})$ was initially swelled in DCM (5 mL) followed by DMF (5 mL). $N$-Fmoc-Asp $\left(\mathrm{O}^{\mathrm{t}} \mathrm{Bu}\right)-\mathrm{OH}(0.032 \mathrm{~g}, 0.078 \mathrm{mmol})$, PyBOP $(0.041 \mathrm{~g}$, $0.078 \mathrm{mmol})$ and DIPEA $(0.014 \mathrm{~mL}, 0.078 \mathrm{mmol})$ in $0.5 \mathrm{~mL}$ DMF was added to the peptide vessel containing resin beads and the coupling reaction was continued for $6 \mathrm{~h}$. The resin beads were washed with DMF $(3 \times 3 \mathrm{~mL})$ followed by washing with isopropanol $(3 \times 3 \mathrm{~mL})$. Completion of peptide coupling reaction was confirmed by performing the Kaiser test (KT). Then a solution of $20 \%$ piperidine in DMF $(1 \times 4 \mathrm{~mL} ; 2 \times 3 \mathrm{~mL})$ was added to the peptide vessel to cleave NHFmoc protecting group. Resin beads were washed with DMF $(3 \times 3 \mathrm{~mL})$ followed by isopropanol $(3 \times 3 \mathrm{~mL})$ and the formation of free amine was confirmed by the Kaiser test. A series of amino acids such as Boc-Dap(Fmoc)-OH (0.033 g, $0.078 \mathrm{mmol})$, Fmoc-Phe-OH (0.030 g, $0.078 \mathrm{mmol})$, Fmoc-Phe-OH (0.030 g, $0.078 \mathrm{mmol})$, Fmoc-8aminocaprylic acid $(0.030 \mathrm{~g}, 0.078 \mathrm{mmol})$, were coupled to the growing peptide chain in a similar way as mentioned before. After the deprotection of Fmoc group from the last amino acid, Fmoc-8-aminocaprylic acid, tris(tert-butyl) protected DUPA 4 (0.023 g, $0.047 \mathrm{mmol})$, PyBOP $(0.041 \mathrm{~g}, 0.079 \mathrm{mmol})$ and DIPEA $(0.014 \mathrm{~mL}, 0.078 \mathrm{mmol})$ in $0.5 \mathrm{~mL}$ DMF was added to the vessel and reacted for $6 \mathrm{~h}$. The completion of reaction was again confirmed by the Kaiser test.

\section{General procedure for peptide cleavage from resin beads.}

A mixture of $9.5 \mathrm{~mL}$ trifluoroacetic acid (TFA), $0.25 \mathrm{~mL}$ triisopropylsilane (TIPS), $0.25 \mathrm{~mL}$ EDT and $0.25 \mathrm{~mL} \mathrm{H}_{2} \mathrm{O}$ was prepared, and $5 \mathrm{~mL}$ of this cocktail solution was added to resin beads and nitrogen was bubbled through the solution for $30 \mathrm{~min}$. Same procedure was repeated twice using $2.5 \mathrm{~mL}$ (15 min each) of cocktail solution. The collected mother liquor from cleavage was evaporated under reduced pressure and the concentrated viscous liquid was precipitated in ice-cold diethylether. The precipitated product was dried under nitrogen atmosphere to afford a solid having yield $70.7 \%(23.7 \mathrm{mg})$ and the crude product was purified through HPLC.

\section{Analytical HPLC method}

The purity of DUPA-SH linker 11 was analyzed using a Dionex HPLC Ultimate 3000 system. Typically, a solution of DUPA-SH linker $11(20 \mu \mathrm{L}, 1.0 \mathrm{mg} / 1.0 \mathrm{~mL})$ in a mixture of $\mathrm{CH}_{3} \mathrm{CN}: \mathrm{H}_{2} \mathrm{O}$ (1: 1) was injected via autosampler and eluted using Dionex Acclaim ${ }^{\circledR} 120$ $\mathrm{C}_{18}, 5 \mu \mathrm{m}, 4.6 \mathrm{~mm} \times 250 \mathrm{~mm}$ analytical column at a flow rate of $1 \mathrm{~mL} / \mathrm{min}$ (mobile phase, $\mathrm{A}=0.1 \%$ trifluoro acetic acid $/ \mathrm{H}_{2} \mathrm{O}$ and $\mathrm{B}=$ acetonitrile). An isocratic flow of $40 \% \mathrm{~B}(\mathrm{v} / \mathrm{v})$ was used during the run for 0 to 4 min and gradually gradient of $\mathrm{B}$ was increased to $100 \% \mathrm{~B}(\mathrm{v} / \mathrm{v})$ over a period of 40-min. The chromatogram of 11 was recorded on the Ultimate $3000 \mathrm{RS}$ variable wavelength detector at $225-280 \mathrm{~nm}$ with $\mathrm{t}_{\mathrm{R}}=10.8 \mathrm{~min}$.

\section{Preparative HPLC method}

The purification of DUPA-SH linker 11 was performed using Buchi Reveleris Prep HPLC System. Crude DUPA-SH linker $11(20 \mathrm{mg})$ was dissolved in 1:1 ratio of $\mathrm{CH}_{3} \mathrm{CN}$ : $\mathrm{H}_{2} \mathrm{O}(1$ $\mathrm{mL}$ ) and injected into the sample injector for elution using RP-PFP (Reverse Phase PentafluoroPhenyl) preparative column (XSelect CSH Prep Fluorophenyl $5 \mu \mathrm{m} \mathrm{OBD,} 19 \mathrm{~mm}$ $\times 150 \mathrm{~mm}$ ). A flow rate of $10 \mathrm{~mL} / \mathrm{min}$ (mobile phase, $\mathrm{A}=0.1 \%$ trifluoro acetic acid $/ \mathrm{H}_{2} \mathrm{O}$ and $\mathrm{B}=$ acetonitrile) is maintained throughout the run and the mobile phase gradient was increased 
from $1 \% \mathrm{~B}(\mathrm{v} / \mathrm{v})$ to $50 \% \mathrm{~B}(\mathrm{v} / \mathrm{v})$ over a period of $40 \mathrm{~min}$. The mobile phase gradient was further increased to $80 \% \mathrm{~B}(\mathrm{v} / \mathrm{v})$ in the next $15 \mathrm{~min}$ and the chromatogram was recorded at $\lambda=280$ or $555 \mathrm{~nm}$. Pure fractions of 11 were collected using automatic fraction collector, acetonitrile was evaporated under reduced pressure and after lyophilization pure conjugate 11 was obtained. HRMS (+ESI) calcd for $[\mathrm{M}-\mathrm{Cl}]^{+}\left(\mathrm{C}_{47} \mathrm{H}_{65} \mathrm{~N}_{9} \mathrm{O}_{17} \mathrm{~S}\right)^{+} 1060.1341$ found 1060.4293 .

\section{Conjugation procedure of DUPA-SH peptide 11 with Qdot-655}

A mixture of QDot 655 (QDot 655 ITK amino (PEG) QDs; Invitrogen, Q21561MP) (1 nmol, $125 \mu \mathrm{L})$ and 4-maleimidobutyric acid N-succinimidyl ester (Sigma Aldrich, M7642) (1 $\mu \mathrm{mol}$ in $200 \mu \mathrm{L}$ of borate buffer, $10 \mathrm{mM}, \mathrm{pH} \mathrm{8.5)}$ was incubated in a $2 \mathrm{~mL}$ Eppendorf tube at room temperature $\left(27^{\circ} \mathrm{C}\right)$ for $2 \mathrm{~h}$ with gentle shaking. The maleimide-QDot 655 intermediate formed was purified immediately by applying the reaction mixture to a desalting column packed with Sephadex G-10 (NAP-10 column, GE Healthcare,17-0854-01) previously equilibrated using 1X PBS, pH 7.4 (Invitrogen, 20012-027). The deepest coloured fractions $(400 \mu \mathrm{L})$ were collected under UV visualisation. For the conjugation reaction, DUPA-SH Linker 11 (1.06 mg, $1 \mu \mathrm{mol})$ was dissolved into $400 \mu \mathrm{L}$ maleimide-QDot 655 mixture, and the $\mathrm{pH}$ was adjusted 7-7.4 using borate buffer $(10 \mathrm{mM}, \mathrm{pH} 8.5)$. The reaction mixture was incubated in an Eppendorf tube at room temperature for $2 \mathrm{~h}$, with gentle shaking. Finally, the mixture was loaded on NAP-10 purification column and the pure NIR-PSMA-QDot bioconjugate $(500 \mu \mathrm{L})$ were collected. After purification, the NIR-PSMA-QDot conjugate was stored in $1 \mathrm{X} \mathrm{PBS}$ at $4^{\circ} \mathrm{C}$, till further use in imaging studies.

\section{UV-Vis Analysis of NIR-PSMA-QDot Complexes - Conjugate formation}

UV-visible spectroscopy was performed with a double-beam Lambda 850 UV/VIS spectrophotometer UV-2600i (Shimadzu, Japan). Conjugated samples, NIR-PSMA-QDot $(1 \mathrm{nM}, 500 \mu \mathrm{L})$, unconjugated sample, QDot $655(1 \mathrm{nM}, 500 \mu \mathrm{L})$ and DUPA-SH linker 11 $(100 \mathrm{nM}, 500 \mu \mathrm{L})$ were analysed in the $200-800 \mathrm{~nm}$ spectral range and emission spectra of all samples were recorded and plotted using GraphPad Prism 6.02 software.

\section{Culture of human cancer cell lines}

LNCaP, PC-3, RAW 264.7, MRC-5, HEK 293 and HEPg2 cells cell lines were purchased from National Centre for Cell Science (NCCS, Pune, India). The cell lines were grown as a monolayer until confluent in sterile filtered RPMI 1640 medium (Invitrogen, 11875093) supplemented with 10\% heat inactivated fetal bovine serum (HIFBS) (Invitrogen, 10270106), $1 \%$ Penicillin-Streptomycin antibiotic $(10,000 \mathrm{U} / \mathrm{mL}$, Invitrogen, 15140122$)$ and $100 \mathrm{mM}$ of sodium pyruvate (Invitrogen, 11360070) in 5\% $\mathrm{CO}_{2}: 95 \%$ air humidified atmosphere, at $37^{\circ} \mathrm{C}$. Cells were passaged using $0.25 \%$ trypsin-EDTA (Thermo Fisher Scientific, 25200114), with all experiments conducted in the range $\mathrm{pX}-\mathrm{Y}$ ?.

\section{Confocal microscopy (CLSM) of PSMA-NIR-QDot in prostate cancer cells}

LNCaP (20,000 cells/well in $0.5 \mathrm{~mL}$ medium) and PC-3 (10,000 cells/well in $0.5 \mathrm{~mL}$ medium) cells were seeded into Nunc Lab Tek II Chambered Coverglass System (ThermoFisher) for $72 \mathrm{~h}$ and $48 \mathrm{~h}$ respectively. Media was replaced with increasing 
concentrations $(0.5,1,5 \mathrm{nM})$ of PSMA-NIR-QDot prepared in medium $(0.5 \mathrm{~mL})$ and incubated at $37{ }^{\circ} \mathrm{C}$ for 45 minutes. For the competition experiment, LNCaP cells were incubated at $37{ }^{\circ} \mathrm{C}$ for $2 \mathrm{~h}$, with 100 -fold excess concentration of 2-PMPA (2-(phosphonomethyl)pentanedioic acid, Sigma Aldrich, SML1612) prior to incubation with PSMA-NIR-Qdots. After rinsing with fresh medium $(3 \times 1.0 \mathrm{~mL})$ to remove unbound conjugate, confocal images were acquired using FV 1000, Olympus using Ex/Em $559 \mathrm{~nm}$ (yellow diode laser) / 575-675 nm.

\section{Evaluation of binding affinity of the PSMA-NIR-QDot in LNCaP cell lines}

LNCaP cells were seeded in T-75 flasks and were grown for $72 \mathrm{~h}$. After $90 \%$ confluency, cells were trypsinized and centrifuged to form a cell pellet. Flow cytometry buffer was prepared by mixing 1 X DPBS $(50 \mathrm{~mL}), 25 \mathrm{mM}$ HEPES buffer $(1 \mathrm{~mL})$ and EDTA $(84 \mathrm{mg})$ and sterile filtered prior to use. $75,000 \mathrm{LNCaP}$ cells in $100 \mu \mathrm{L}$ of the medium were suspended in each of the Eppendorf tubes. PSMA-NIR-QDot ( $400 \mu \mathrm{L}$ medium) was added to the cell suspension $(100 \mu \mathrm{L})$ to a final concentration of $1-1000 \mathrm{nM}$ and incubated for $1 \mathrm{~h}$ at $4{ }^{\circ} \mathrm{C}$. The treated cell suspension in each tube was centrifuged, washed $(3 \times 1 \mathrm{~mL})$ and resuspended in ice cold FACS buffer $(1 \mathrm{~mL})$ for flow cytometry analysis. The mean fluorescence intensity was measured for each sample concentration (10,000 events) using flow cytometer (LSR Fortessa, BD Biosciences).

For competition or blocking experiment, the cell suspension in each tube $(75,000$ cells in $100 \mu \mathrm{L}$ medium) was treated with 100 -fold excess 2-PMPA (final vol $=300 \mu \mathrm{L}$ medium) and incubated for $2 \mathrm{~h}$ at $4{ }^{\circ} \mathrm{C}$. After treatment with 2-PMPA, PSMA-NIR-QDot (300 $\mu \mathrm{L}$ medium) was added (final vol $=600 \mu \mathrm{L}$ medium) to make final concentrations of $1-1000 \mathrm{nM}$ in each tube and further incubated for $1 \mathrm{~h}$ at $4{ }^{\circ} \mathrm{C}$. The treated cell suspension in all tubes were centrifuged, washed $(3 \times 1 \mathrm{~mL})$ and resuspended in ice cold FACS buffer $(1 \mathrm{~mL})$ for flow cytometry analysis. The mean fluorescence intensity was measured for each sample concentration (10,000 events) using flow cytometer (LSR Fortessa, BD Biosciences). Experiment was performed in triplicates. A plot of mean fluorescence intensity (A.U.) versus concentration of the test article afforded a dissociation constant $\left(\mathrm{K}_{\mathrm{D}}\right)$ value of $15 \mathrm{nM}$ for the PSMA-NIR-QDot in LNCaP cells. The method of non-linear regression analysis was employed assuming one-site specific binding during the calculation of $\mathrm{K}_{\mathrm{D}}$ using GraphPad Prism 6.02 software.

\section{Biocompatibility/ cell viability assays}

The biocompatibility of PSMA-NIR-QDot was assessed by incubating the nanoprobe with RAW 264.7, MRC-5, HEK 293 and HEPg2 cells. The 3-(4,5-dimethylthiazolyl-2)-2,5diphenyltetrazolium bromide (MTT) assay was performed to evaluate cell viability in the presence of PSMA-NIR-QDot. The cells were seeded into 96-well flat bottom culture plates at a density of 10000 cells per well, with $200 \mathrm{~mL}$ of medium (10\% RPMI 1640). Cells were cultured for $48 \mathrm{~h}$ at $37{ }^{\circ} \mathrm{C}$ humid atmosphere containing $5 \% \mathrm{CO}_{2}$. Cells were incubated with different concentrations of PSMA-NIR-QDot, $1 \mathrm{nM}$ to $500 \mathrm{nM}$ for $12 \mathrm{~h}$ prior to MTT assay. Briefly, the medium in each well was replaced and $50 \mu \mathrm{L}$ of MTT solution $(5 \mathrm{mg} / \mathrm{mL})$ were 
added to each well. After $4 \mathrm{~h}$ of incubation, the solution was removed and $200 \mu \mathrm{L} / \mathrm{well}$ of DMSO were added to dissolve the resulting crystals. The reduction of MTT to its insoluble formazan product was quantified by measuring the sample absorbance at $570 \mathrm{~nm}$ using a microwell plate reader (Tecan Life sciences).

\section{Microwell Fabrication in Agarose and Developing LNCaP Spheroids}

Agarose (1.125 g, low EEO, routine use, Sigma Aldrich, A5093) was measured and dissolved in $75 \mathrm{~mL}$ of sterile 1X DPBS ( $\mathrm{pH}=7.4$, Invitrogen, 21600010) to make $1.5 \%$ solution. The solution was sterilized by autoclave. Without allowing the autoclaved solution to cool, molten agarose was poured in a glass petridish $(100 \mathrm{~mm}$, dia) in sterile LAF chamber. Sterile wooden hair-brush/master template (Sears, wooden baby brush, model no. B01BLTN3EI) diameter of bristle/spherical tip was measured using Vernier callipers, (2400 $\mathrm{mm}$ and $1500 \mathrm{~mm}$ ) for making $(1200 \mu \mathrm{m}$ and $900 \mu \mathrm{m}$ dia) spheroids respectively, were placed in petri dish, immersing the bristle/spherical tip of the brush $2.5 \mathrm{~mm}$ (depth can be pre-marked on petri dish side for reference) deep in agarose. The system was left undisturbed for $20 \mathrm{~min}$, till agarose mold solidified. After $20 \mathrm{~min}$, the comb/master template was removed and rows of micro-arrays impressions in agarose sized 2100 was observed. An agarose mold piece containing 20 microwells/1 microarray was carefully cut from the petri plate using a steel blade and placed in each well of a 6-well plate (Nunc Nalgene). The 6-well plate was sterilized for $3 \mathrm{~h}$ under UV, and $3 \mathrm{~mL}$ of RPMI 1640 medium was added to each well, immersing agarose chip and allowing the system to equilibrate before cell seeding. The spent medium was removed after equilibration from each well. LNCaP growing in a T-75 flask were trypsinized and cell counting was performed. For cell seeding, 20,000 cells in $5 \mu \mathrm{L}$ medium/well was added in each array of agarose chip for forming $1200 \mu \mathrm{m}$-dia spheroid. The agarose chip with seeded cells was immersed in 10\% RPMI ( $3 \mathrm{~mL} /$ well of 6 -well plate). The 6-well plate containing the chip with the seeded cells was placed back in the incubator $\left(37{ }^{\circ} \mathrm{C}, 5 \% \mathrm{CO}_{2}\right)$ overnight to allow for cell aggregation. Media was replaced every 2 days until spheroids were needed for experiments.

\section{Spheroid viability measurements}

PCa cancer spheroids viability and growth in agarose microwells were monitored in $2100 \mu \mathrm{m}$ diameter wells. To determine the viability, spheroids $(\mathrm{n}=5)$ grown were immersed in fluorescein diacetate (FDA) $(5 \mathrm{mg} / \mathrm{mL}) /$ propidium iodide $(\mathrm{PI})(2 \mathrm{mg} / \mathrm{mL})$ in $1 \mathrm{X}$ DPBS staining solution for 15 minutes in dark. Spheroids were then rinsed $(5 \times 1.0 \mathrm{~mL})$ with fresh

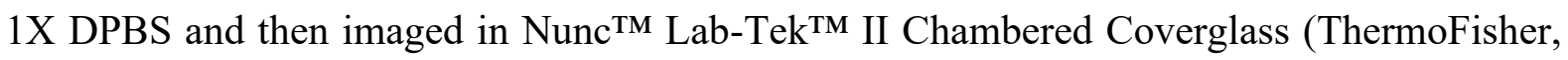
155382) using laser scanning confocal microscopy (FV 1000, Olympus). The imaging parameters were as follows: FDA, ex/em 488/ 500-560 nm and for PI 559/ 575-675 nm. Z-scan imaging parameter: Z-dimension was 6739.55 - $6640.55 \mu \mathrm{m}, 3.0(\mu \mathrm{m} /$ slice $)$. Images were evaluated using Olympus Fluoview ver.4.2.

\section{Multiphoton-deep tissue penetration analysis of PSMA-NIR-QDot in LNCaP spheroids}

LNCaP spheroids $(1200 \mu \mathrm{m})$ grown for $48 \mathrm{~h}$ were harvested and incubated in a $1.5 \mathrm{~mL}$ Eppendorf with $100 \mathrm{nM}$ of PSMA-NIR-QDot solution for $2 \mathrm{~h}$, at $37{ }^{\circ} \mathrm{C}, 5 \% \mathrm{CO}_{2}$. After incubation, unbound conjugate was washed $(3 \times 1.0 \mathrm{~mL})$ with fresh medium by allowing the spheroids to settle at the bottom of the Eppendorf by decanting spent medium. The spheroids 
were imaged in Nunc Lab Tek II Chambered Coverglass System using multiphoton imaging, using laser scanning microscopy (FV 1000, Olympus), at $\lambda_{\mathrm{Ex}} 790 \mathrm{~nm}$ using Ti(titanium): Sapphire mode-locked pulsed laser, and emission wavelength was collected at bandpass filter

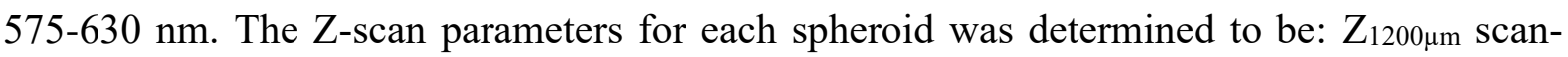
6265.24 - $6389.24 \mu \mathrm{m}, 3.0(\mu \mathrm{m} /$ Slice $)$. Images were processed using Olympus Fluoview ver.4.2. and ImageJ analysis software.

\section{Competition study of multiphoton penetration analysis of PSMA-NIR-QDot}

LNCaP spheroid $(900 \mu \mathrm{m})$ were harvested after $48 \mathrm{~h}$ of growth and incubated with $10 \mu \mathrm{M}$ 2-PMPA (100-fold excess) for $2 \mathrm{~h}$ prior to incubation with $100 \mathrm{nM}$ of PSMA-NIR-QDot at $37{ }^{\circ} \mathrm{C}, 5 \% \mathrm{CO}_{2}$. The unbound PSMA-NIR-QDot was washed $(3 \times 1.0 \mathrm{~mL})$ with fresh medium by allowing the spheroids to settle at the bottom of the Eppendorf by decanting spent medium. The spheroids were imaged using multiphoton laser scanning microscopy (FV 1000, Olympus), at $\lambda_{\mathrm{ex}} 790 \mathrm{~nm}$ using Ti(titanium): Sapphire mode-locked pulsed laser, and emission wavelength was collected at bandpass filter $575-630 \mathrm{~nm}, \mathrm{Z}$ Dimension parameters: 6476.7 - $6140.7 \mu \mathrm{m}, 0.5$ ( $\mu \mathrm{m} /$ slice). Images were processed using Olympus Fluoview ver.4.2. and Image J analysis software.

\section{Results and Discussion}

\section{Probe design:}

The development of sensitive, accurate and specific imaging probes that lack the intrinsic limitations of organic dyes and fluorescent proteins is of the utmost interest in areas of molecular imaging and medical diagnostics of PCa. Here we describe the use of nanometersized semiconductor particles covalently linked to biorecognition molecules such as peptides linked to small molecule homing ligands. ${ }^{32}$ In comparison with organic fluorophores, QDots have unique optical and electronic properties, such as size- and composition-tunable fluorescence emission from visible to infrared wavelengths, large absorption coefficients across a wide spectral range and very high levels of brightness and photostability. ${ }^{33}$ 


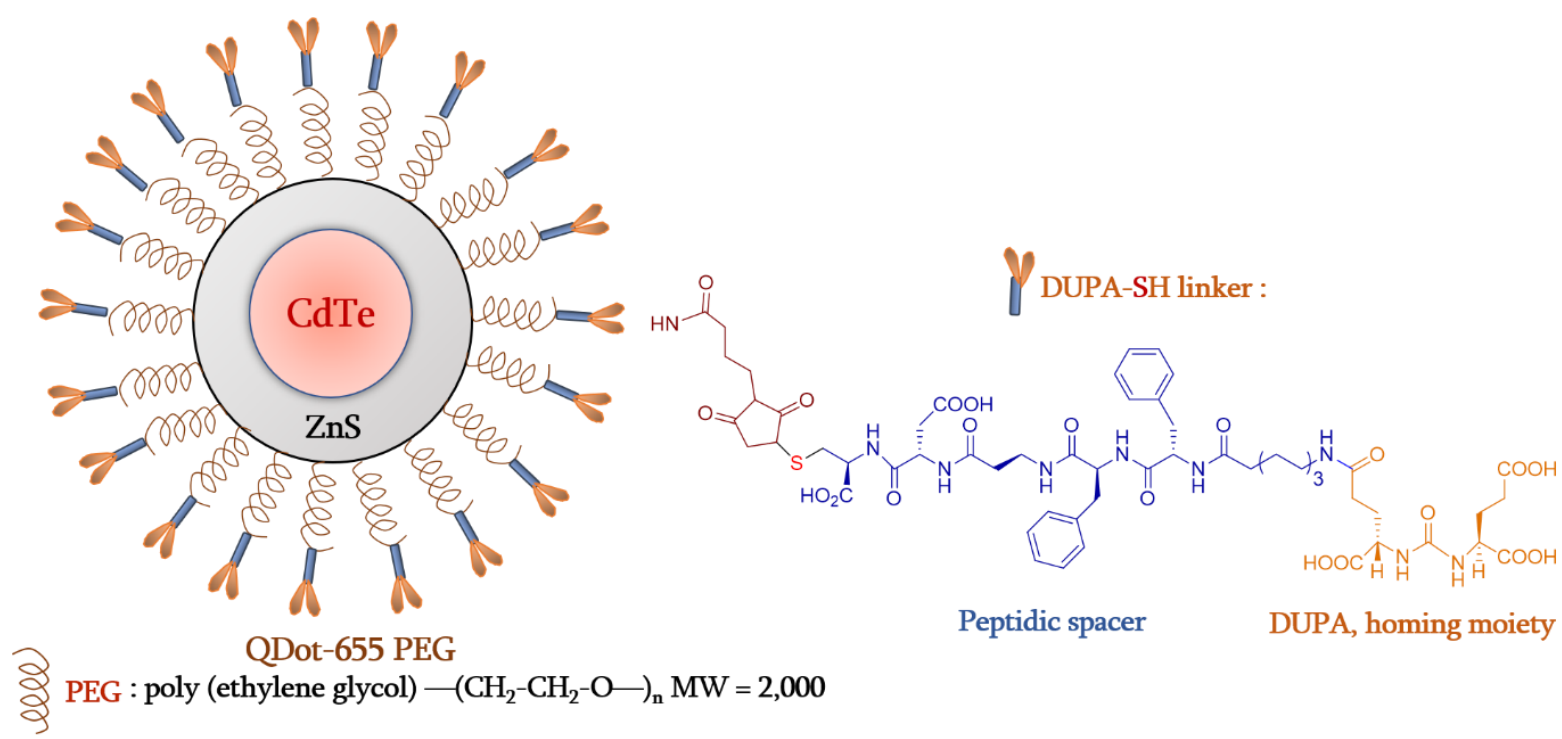

QDot-NIR-PSMA

Figure 1: Schematic illustration of DUPA-SH-linker 11 conjugated QDot-655 (QDotNIR-PSMA) for NIR fluorescence imaging of PCa tumour

We have developed bioconjugated QDot probes (QDot-NIR-PSMA, figure 1) suitable for in vivo targeting and imaging of human prostate cancer cells for fluorescence guided surgery and medical diagnostics. This new class of NIR QDot bioconjugate probes contains targetingligand DUPA (2-[3-(1, 3-dicarboxy propyl)ureido] pentanedioic acid) for PSMA biomarker recognition $\left(\mathrm{Ki}=8 \mathrm{nM}, \mathrm{IC}_{50}=47 \mathrm{nM}\right)$ on tumor cells, multiple PEG molecules for improved biocompatibility and circulation. ${ }^{34}$ At this level of conjugation, PEG does not

Qdot ${ }^{\circledR} 655$ ITK $^{\mathrm{TM}}$ amino (PEG) quantum dots are the ideal fluorophores for preparing targeted NIR bioconjugates which can selectively image PSMA biomarker over-expressed on PCa cells. These probes are functionalized with amine-derivatized PEG, which prevents nonspecific interactions and provides a convenient handle for conjugation. The amino QDot-655 also react efficiently with heterobifunctional crosslinker 4-maleimidobutyric acid N-hydroxysuccinimide ester (GMBS) which is reactive towards sulfhydryl group present on DUPA-chelating linker. During conjugation, DUPA-peptidic spacer-SH is attached to distal termini of PEG, to reduce any interference of PEG-chains during ligand binding with PSMA protein tunnel.

\section{Synthesis of DUPA-SH-chelating linker}

Even though QDots have long been used for in vitro imaging applications such as labelling cells (fixed and live) and tissues, multicolor cell imaging, (FRET)-based sensing, etc, in vivo targeting and imaging using QDot- based probes has not become very popular. ${ }^{35-37}$ Small molecule targeted peptides are potentially better as targeting moieties because tens or even hundreds of small-molecule peptides can be linked to the surface of one QDot and may exhibit stronger binding affinity and better targeting efficacy because of the poly-valency effect. ${ }^{38}$ Hence, to construct a small-molecule targeted QDot imaging probe, it is essential to develop the small-molecule peptidic construct prior to conjugation with QDot 655. For this 
purpose, DUPA (2-[3-(1, 3-dicarboxy propyl)ureido] pentanedioic acid), a glutamate-urea ligand has one of the highest affinity for PSMA, $\left(\mathrm{K}_{\mathrm{i}}=8 \mathrm{nM}\right.$ and $\left.\mathrm{IC}_{50}=47 \mathrm{nM}\right)$, it has been used as a homing moiety to target the peptide bioconjugate to cancer cells. ${ }^{28}$ The synthetic scheme for synthesizing DUPA targeting ligand is outlined in Supporting Information (S1). The $\gamma$-carboxylic group of DUPA has been used as a handle to attach a polypeptide chain of seven amino acids to which NIR-QDot 655 has been linked. The final targeting peptide-linker 11 was assembled by an elaborate SPPS strategy, shown in Scheme 1.

SPPS of 11 was performed using commercially available chlorotrityl resin, H-Cys(Trt)-2$\mathrm{Cl}$-Trt resin (5). It is to be noted here that the selection of H-Cys(Trt)-2-Cl-Trt resin finally yields an SH group in the peptide handle or chelating core of compound $\mathbf{1 1}$ which is utilized for the conjugation of Qdot ${ }^{\circledR} 655$ ITK $^{\mathrm{TM}}$ amino (PEG) via GMBS in a later step. ${ }^{39}$ DUPA-SH linker 11 was prepared in a continuous solid phase synthetic strategy, wherein, the primary amino group present in $\mathbf{5}$ was coupled with Fmoc-Asp $\left(\mathrm{O}^{t} \mathrm{Bu}\right)-\mathrm{OH}$ using PyBOP as a coupling agent to form dipeptide $\mathbf{6}$. The NHFmoc amino group in $\mathbf{6}$ was deprotected using a solution of $20 \%$ piperidine in DMF and the Fmoc free amino group generated from $\mathbf{6}$ was coupled with Fmoc-Boc(Tfa)-OH using standard coupling reagent to provide tripeptide chain $7 .{ }^{40}$ The tripeptide 7 were tethered sequentially to two phenyalanine residues, 8-aminocaprylic acid and finally to DUPA 4, to provide polypeptide chain 11. The addition 8-aminocaprylic acid ensures adequate distance between targeting ligand and peptidic spacer, so that binding affinity is not compromised. The attachment of two phenylalanine moieties adds the necessary hydrophobic interactions with the binding pocket present in $20 \AA$ tunnel of the PSMA protein. ${ }^{41}$ 


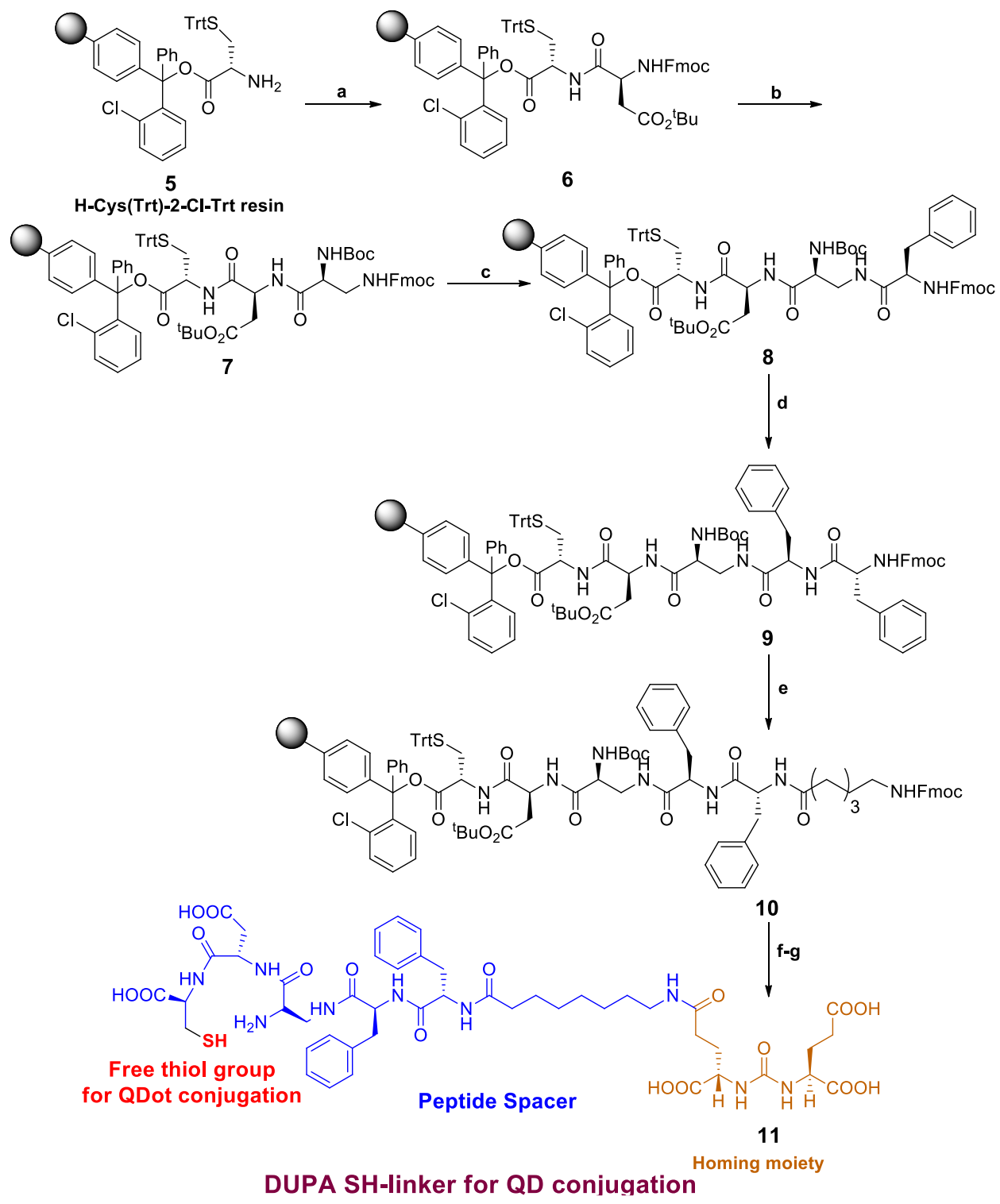

\section{Scheme 1. Synthesis of PSMA targeting DUPA chelating conjugate 11}

Reagents and conditions: (a) Fmoc-Asp $(\mathrm{O} t-\mathrm{Bu})-\mathrm{OH}$, PyBOP, DIPEA, DMF, 6 h; (b) (1) $20 \%$ piperidine in DMF, rt, $1 \times 4 \mathrm{~mL}, 10 \mathrm{~min} ; 2 \times 3 \mathrm{~mL}, 5 \mathrm{~min}$; (2) Boc-Dap(Fmoc)-OH, PyBOP, DIPEA, DMF, 6 h; (c) (1) $20 \%$ piperidine in DMF, rt, $1 \times 4 \mathrm{~mL}, 10 \mathrm{~min} ; 2 \times 3 \mathrm{~mL}, 5 \mathrm{~min}$; (2) FmocPhe-OH, PyBOP, DIPEA, DMF, 6 h; (d) (1) $20 \%$ piperidine in DMF, rt, $1 \times 4 \mathrm{~mL}, 10 \mathrm{~min}$; $2 \times 3$ mL, 5 min; (2) Fmoc-Phe-OH, PyBOP, DIPEA, DMF, 6 h; (e) (1) $20 \%$ piperidine in DMF, rt, $1 \times 4$ $\mathrm{mL}, 10 \mathrm{~min} ; 2 \times 3 \mathrm{~mL}, 5 \mathrm{~min}$; (2) Fmoc-8-aminocaprylic acid, PyBOP, DIPEA, DMF, 6 h; (f) (1) $20 \%$ piperidine in DMF, rt, $1 \times 4 \mathrm{~mL}, 10 \mathrm{~min} ; 2 \times 3 \mathrm{~mL}, 5 \mathrm{~min}$; (2) $\mathrm{DUPA}(\mathrm{Ot}-\mathrm{Bu})_{3}-\mathrm{OH}, \mathrm{PyBOP}$, DIPEA, DMF, $6 \mathrm{~h}$; (g) (1) TFA/TIS/EDT/ $\mathrm{H}_{2} \mathrm{O}(9.25: 0.25: 0.25: 0.25,1 \times 5 \mathrm{~mL}, 30 \mathrm{~min} ; 2 \times 5 \mathrm{~mL}, 5$ $\mathrm{min})$; (2) evaporate TFA; (3) precipitate in ice cold diethyl ether.

DUPA-SH linker 11 was obtained by cleaving the polypeptide from the H-Cys(Trt)-2-Cl-Trt resin while simultaneously deprotecting all Boc, tert-butylcarboxylic acid groups, and Trt groups present in diaminopropionic acid, aspartic acid and cysteine thiol amino acids, using a cleaving cocktail TFA:TIS: $\mathrm{H}_{2} \mathrm{O}$ (92.5:2.5:2.5:2.5). in water to give 11 in high yield and purity. The final product $\mathbf{1 1}$ was concentrated under reduced pressure to evaporate TFA and 
ice-cold ether was added to precipitate the DUPA-SH linker $\mathbf{1 1}$ as a creamish-white solid. The crude product 11 was purified through Buchi reveleris prep instrument using RP-PFP preparative column (Xselect CSH Prep Fluorophenyl $5 \mu \mathrm{m}, 19 \mathrm{~mm} \times 150 \mathrm{~mm}$ ) at $\lambda=280$ or $555 \mathrm{~nm}$.

\section{Conjugation of Qdot-655 with DUPA-SH-chelating linker}

To effectively recognize and enable non-invasive imaging of PSMA protein target, NIRQdots need to be conjugated with DUPA-SH-chelating linker 11. ${ }^{42}$ Taking into account the surface properties of QDots and the free-thiol functional group within DUPA-SH-linker 11, a conjugation strategy was devised (Scheme 2).

Procedure for developing PSMA-NIR-Qdot employs attaching a thiol containing DUPA-SHlinker 11 to amino functionalized QDots. Qdot-655 contains a polyethylene glycol (PEG; MW $2 \mathrm{kDa}$ ) spacer covalently attached to the QDot surface, resulting in improved stability in high-salt buffers and reduced nonspecific binding. It is known that modified QDots that do not contain PEG spacers may precipitate from high-salt buffers. Moreover, these QDots also significantly more nonspecific binding to cells compared to the amino-functionalized QDots with PEGylation which makes biological experimental data harder to interpret. ${ }^{43}$ Conjugation of Qdot-655 and the DUPA-SH linker 11 through a heterobifunctional crosslinker (4-maleimidobutyric acid N-succinimidyl ester, GMBS) is a convenient and widely used approach. $^{44}$

Amine-modified QDot-655 (emission maximum at $655 \mathrm{~nm}$, Quantum Dot Corp., Hayward, CA) was first conjugated to a heterobifunctional cross-linker, 4-maleimidobutyric acid $\mathrm{N}$ hydroxysuccinimide ester, yielding a maleimide-nano-crystal surface. The maleimide-Qdot655 intermediate is isolated by size-exclusion chromatography (SEC) using NAP-10 column (GE Healthcare, Piscataway, NJ). The maleimide-functionalized QDot-655 was allowed to react with DUPA-SH linker $\mathbf{1 1}$ for $1 \mathrm{~h}$ at $\mathrm{pH} 7.5$ and the final conjugate was purified using size-exclusion chromatography.

In order to increase the reactivity of QDots towards maleimide-functionalized biomolecules, the mixture was first reduced by incubation with tris(2-carboxyethyl) phosphine hydrochloride (TCEP). TCEP was chosen over other reducing agents such as DTT since it prevents re-oxidation of generated thiols, thereby prolonging the half-life of the transient thiol species. The solution was left under constant stirring for $30 \mathrm{~min}$ at room temperature. 


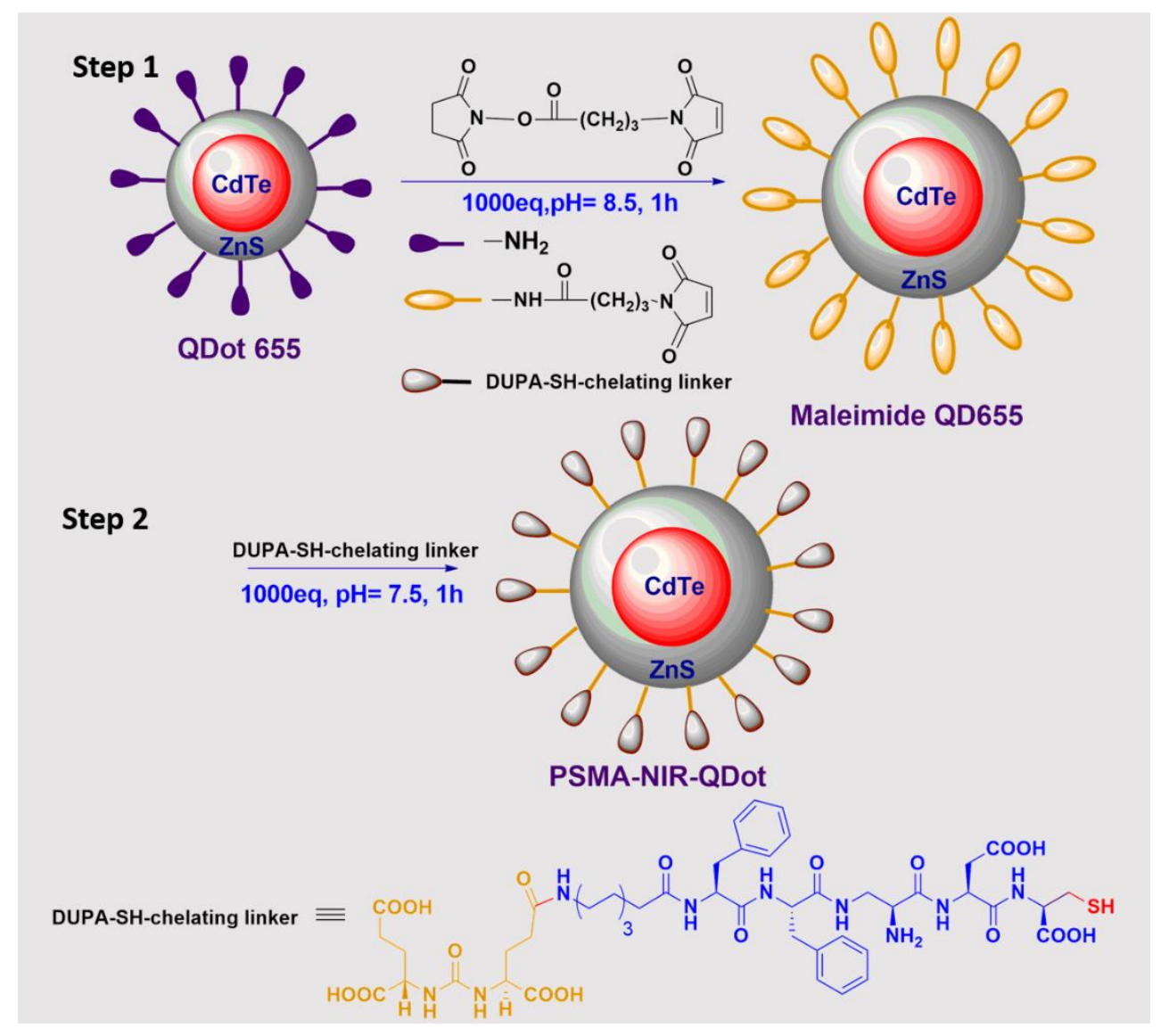

Figure 2: Schematic illustration to prepare PSMA-NIR-Qdot for targeted deep tissue imaging studies. A two-step synthetic scheme for conjugation of Qdot ${ }^{\circledR} 655$ ITK $^{\mathrm{TM}}$ amino (PEG) with freethiol of DUPA-SH-chelating linker 11 using heterobifunctional crosslinker 4-maleimidobutyric acid $\mathrm{N}$-succinimidyl ester (GMBS).

This conjugation strategy is very simple and unlike conventional conjugation procedures involving laborious purification steps, the PSMA-NIR-QDots are purified by size-exclusion principle using Sephadex NAP-10 columns. After purification, 300-500 $\mu \mathrm{L}$ fractions are isolated having concentrations varying from $500 \mathrm{nM}$ to $5 \mu \mathrm{M}$ and the most concentrated fractions are used for in vitro biological applications.

\section{Characterisation of PSMA-NIR-Qdot using fluorescence spectroscopy.}

PSMA-NIR-Qdots were synthesized and purified by Size-exclusion chromatography (SEC) technique using Sephadex NAP-10 columns (Figure 2). In reactions with high yield of conjugation, nanoparticle size increases due to additional layer of DUPA-SH-chelating linker moiety. This facilitates purification of PSMA-NIR-QDot from unreacted DUPA-SH-linker. ${ }^{45}$ 

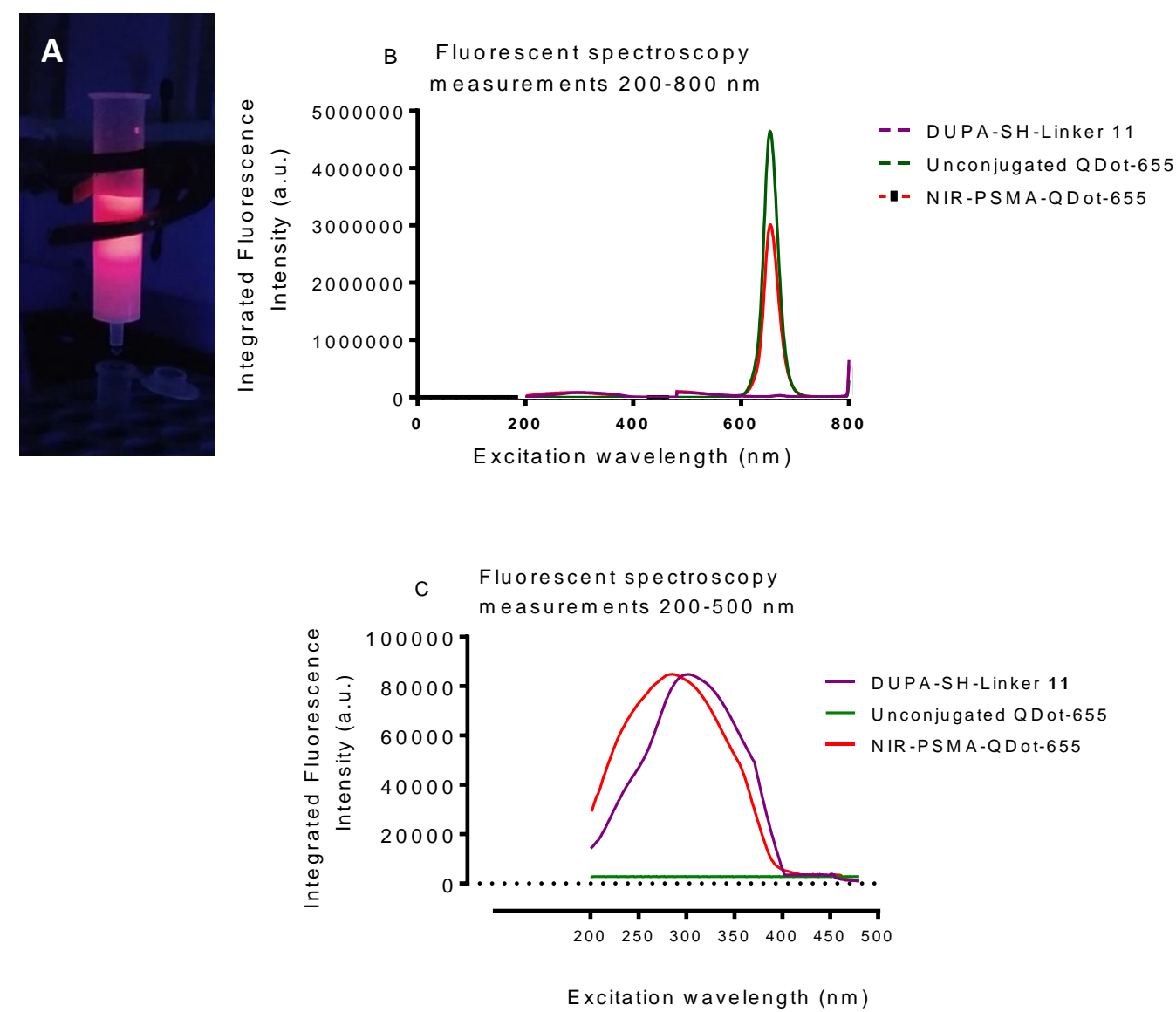

Figure 3: Purification and characterisation of PSMA-NIR-QDot. (A) Purification of PSMA-NIR-QDot by NAP-10 column under UV $\left(\lambda_{\mathrm{nm}}=200-400 \mathrm{~nm}\right)$. (B) Fluorescence spectroscopy measurements of unconjugated QDot-655, DUPA-SH-chelating linker and PSMA-NIR-QDot bioconjugate from 200-800 nm range. (C) 200-570 nm range of unconjugated QDot-655, DUPA-SH-chelating linker and PSMA-NIR-QDot bioconjugate, showing difference in fluorescence intensity after conjugation.

After the reaction mixture is loaded on to the equilibrated column, Figure 3A shows extraction of purified PSMA-NIR-QDot from NAP-10 by collecting the brightest fractions made visible by UV light at range $200-400 \mathrm{~nm}$. The concentrations of the collected fractions were first determined using serial dilutions (0.01 and $10 \mathrm{nM})$ of QDot 655 solution as standard. PSMA-NIR-QDot concentrations were plotted in triplicate using standard curve. The collected fractions range between $500 \mathrm{nM}$ to $5 \mu \mathrm{M}$.

The successful conjugation of DUPA-SH-chelating linker with QDot 655 was verified by photoluminescence studies by spectrofluorometer (Figure 1, B and C). Figure 1 shows the fluorescence intensity spectra over 400-800 nm wavelength for a concentration of $100 \mathrm{nM}$. It can be seen that both QDot-655 unconjugated and PSMA-NIR-QDot show an emission maximum at $655 \mathrm{~nm}$, confirming conjugation of the sample. Another characteristic seen in (Figure 1, C) is that a magnified view of 200-550 $\mathrm{nm}$ range shows that DUPA-SH-linker 11 has a characteristic peaking at $290 \mathrm{~nm}$, due to presence of aromatic amino acid, phenylalanine whose emission maxima is at $280 \mathrm{~nm}$ in peptide linker. Interestingly, PSMA-NIR-QDot also 
shows the same peaking at $290 \mathrm{~nm}$, indication successful conjugation on surface of QDot655.

\section{PSMA-NIR-QDot affinity and uptake studies in vitro in PCa cell lines}

\section{Uptake studies of PSMA-NIR-QDot using confocal laser scanning microscopy (CLSM)}

To explore the potential of PSMA-NIR-QDot in real time targeted imaging and detection of PCa cells, PSMA-NIR-QDot was incubated in PSMA ${ }^{+}$LNCaP cells for 1 hour for three different concentrations $(0.5,1,5 \mathrm{nM}$, figure 4A-C). Figure 4A, depicts the delivery of PSMA-NIR-QDot in PCa cells via receptor mediated endocytosis negating any possibility of non-specific uptake. This assures minimal or negligible uptake of the nanoprobe by nonmalignant or normal tissues when used as a diagnostic agent or for intra-operative identification of prostate malignancies during surgical resection of tumour.

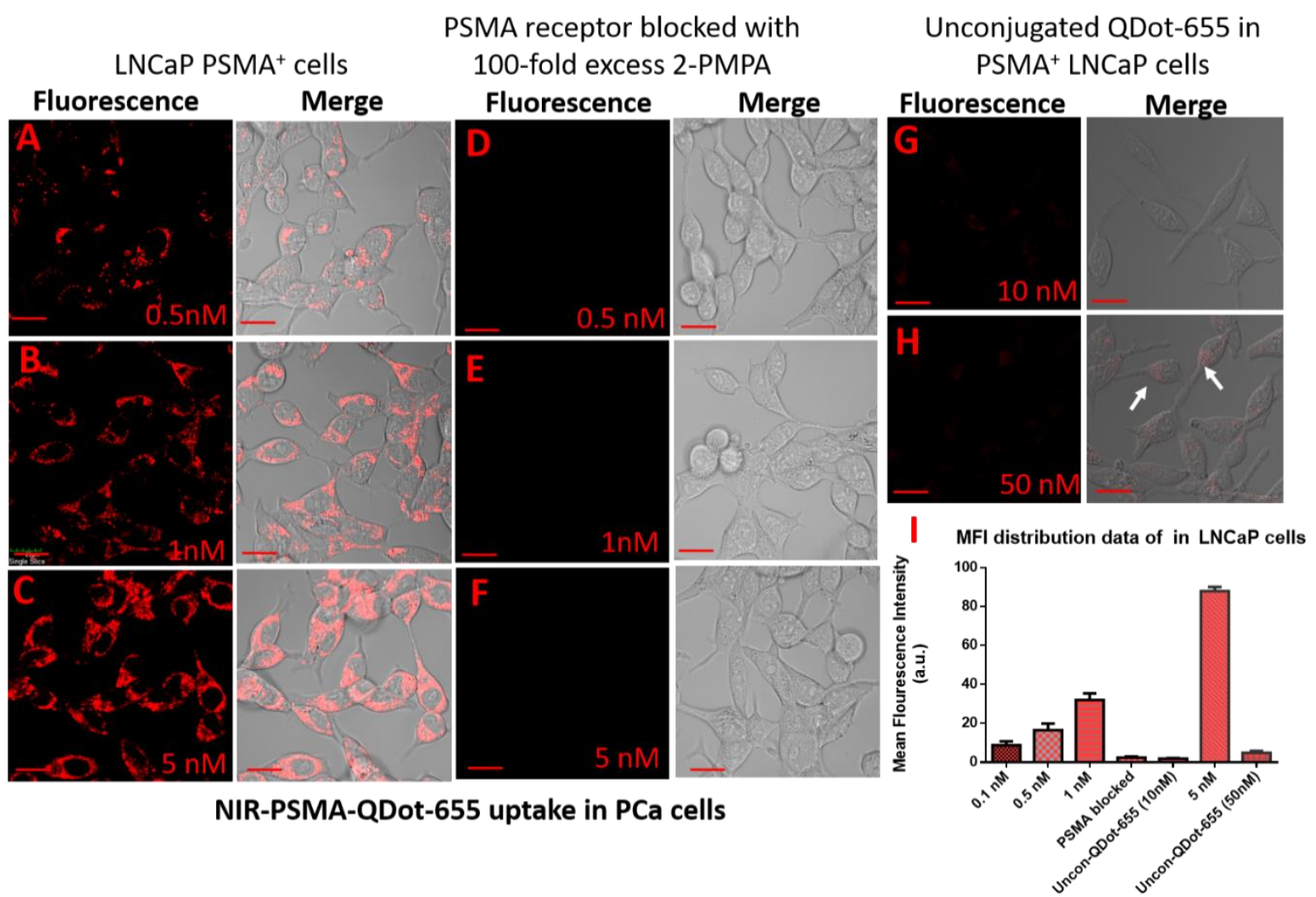

Figure 4: In vitro imaging studies on 2D monolayer cells using PSMA-NIR-QDot. (A), (B), (C) CLSM images of LNCaP cells after $1 \mathrm{~h}$ incubation with $0.5 \mathrm{nM}, 1 \mathrm{nM}$ and $5 \mathrm{nM}$ of PSMA-NIR-QDot respectively. Panel (D),(E),(F) shows images of LNCaP cells with NIR-PSMA-QDot, after PSMA receptors have been blocked with 100 times excess 2-PMPA. Panel $(\mathrm{G}),(\mathrm{H})$ shows CLSM images of LNCaP cells after $1 \mathrm{~h}$ incubation with $10 \mathrm{nM}, 50 \mathrm{nM}$ unconjugated QDot-655 after 1 hour. The "merge" column images show composites of the brightfield and fluorescence images. (I) Bar graph of mean fluorescence intensities (MFI) of PSMA-NIR-QDot for concentrations $0.1 \mathrm{nM}, 0.5 \mathrm{nM}, 1 \mathrm{nM}, 5 \mathrm{nM}$ and $10 \mathrm{nM}, 50 \mathrm{nM}$ of unconjugated QDot655 PSMA in PSMA ${ }^{+}$LNCaP cells and blocked LNCaP cells. MFI values were corrected for autofluorescence. Results are expressed as mean \pm S.D. $(n=5)$. Scale bar represents $30 \mu \mathrm{m}$. 
Close observation of panel A Merge and Fluorescence column shows fluorescence signal, i.e. receptor mediated uptake even at $0.5 \mathrm{nM}$ incubation of NIR-PSMA-QDot, indicating it to be an imaging tool of high potency. Panels $B$ and $C$ also show a 2-fold and 10-fold increase in NIR-PSMA-QDot concentration has led to a visible saturation of endosomes in the cytoplasmic compartment in comparison to panel A.

Competitive binding study was performed for evaluating total uptake of NIR-PSMA-QDot vs blocking of PSMA with 100-fold excess of competitor 2-PMPA for $2 \mathrm{~h}$ on LNCaP cells, prior to incubation with NIR-PSMA-QDot (panel D-F). Significant blocking of binding was observed for bioconjugate (panel D-F). Panels $\mathrm{G}$ and $\mathrm{H}$ also show images after incubating $5 \mathrm{nM}$ and $10 \mathrm{nM}$ of unconjugated QDot 655, for 1 hour in PSMA ${ }^{+} \mathrm{LNCaP}$ cells. This confirms shows that ligand binding and compound internalization are highly PSMA-specific, as virtually no background fluorescence was detected in Panel G-H incubated under same conditions.

The MFI distribution data in Figure 4I measured using ImageJ software, shows that LNCaP cells pre-incubated with 100-fold antagonist 2-PMPA and in unconjugated QDot-655 (10 nM and $50 \mathrm{nM}$ ) showed the least cell fluorescence. Whereas MFI bars for concentrations $0.1 \mathrm{nM}$, $0.5 \mathrm{nM}, 1 \mathrm{nM}, 5 \mathrm{nM}$ of NIR-PSMA-QDot consequently showed 5- to 20-fold higher integrated density values. The extremely low uptake in PSMA-blocked LNCaP and unconjugated-QDot-655 incubation also demonstrate the specificity of the NIR-PSMA-QDot to PCa cells, and confirms that NIR-PSMA-QDot uptake and internalization is via DUPAligand binding to PSMA receptor.

\section{Binding affinity and selectivity study of NIR-PSMA-QDot in PSMA+ LNCaP cells}

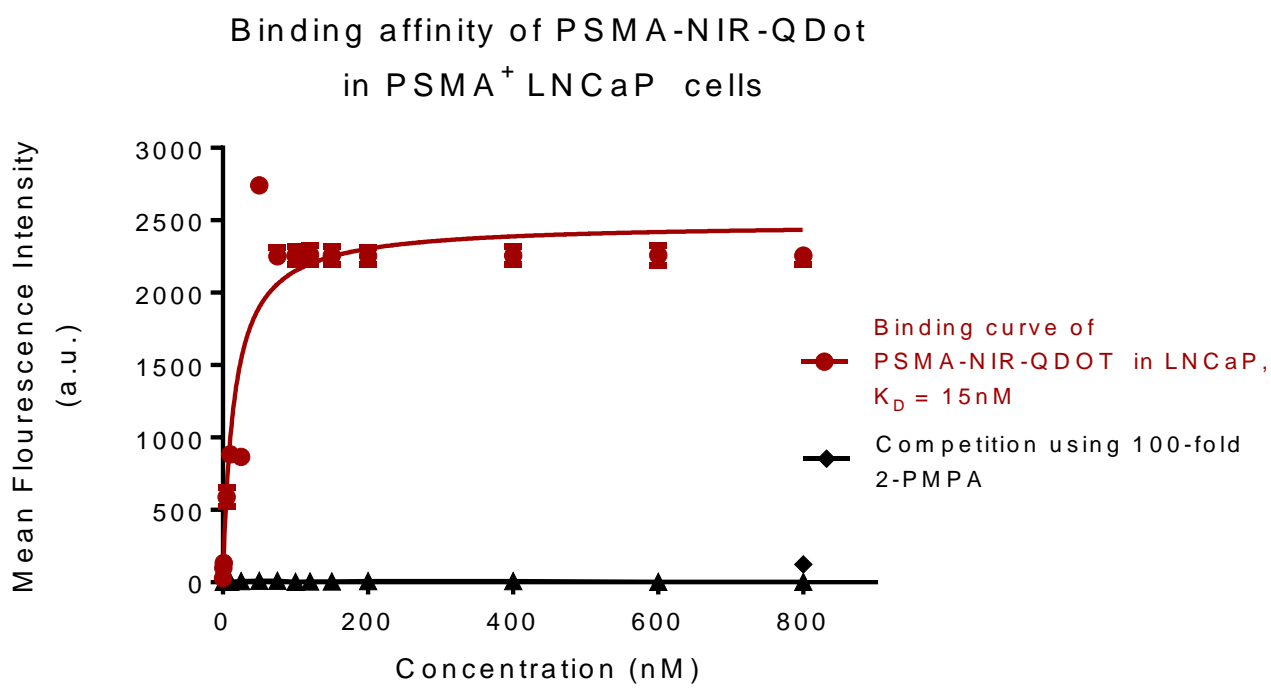

Figure 5: fluorescence binding experiments of NIR-PSMA-QDot using flow cytometric measurements in PSMA ${ }^{+}$LNCaP cells. MFI of 12 for (1-1000) nM concentration were measured with FACS Fortessa flow cytometer. Red curve represents saturation binding graph of NIR- 
In an effort to evaluate the specificity of PSMA-NIR-QDot for prostate cancer, PSMA expression in LNCaP was first examined by flow cytometry (figure 5). Due to moderate PSMA expression levels and better tumorigenic capacity with low necrosis, LNCaP is selected as the primary cell line to characterize PSMA-NIR-QDot. The affinity of PSMANIR-QDot for PSMA was evaluated by incubating increasing concentrations of nanoprobe from $1 \mathrm{nM}$ to $1000 \mathrm{nM}$ with LNCaP cells and analysing for cell bound fluorescence by flow cytometry. PSMA-NIR-QDot was able to bind to PSMA receptor on LNCaP cells with very high affinity $\left(\mathrm{K}_{\mathrm{d}}=15 \mathrm{nM}\right)$, whereas it did not bind to LNCaP cells blocked with 100 -fold excess of 2-PMPA, confirming specificity to PSMA.

\section{Toxicity and biocompatibility analysis of PSMA-NIR-QDot in various cell lines}

The biocompatibility of PSMA-NIR-QDot was evaluated by using two primary cell lines, RAW 264.7 macrophages and MRC-5 lung fibroblast cells and two immortal cell lines, HEK 293 and hepatocyte cells HEPg2. It can be observed from figure 6 that all the four cell lines were biocompatible when incubated with HeLa cells at $12 \mathrm{~h}$, also for all the tested concentrations (1-500 nM). Moreover, PSMA-NIR-QDot did not reveal any toxicity towards non-cancer human cells, RAW 264.7 and MRC-5.

\section{Cell Viability study of NIR-PSMA-QDot \\ after $12 \mathrm{~h}$ incubation}

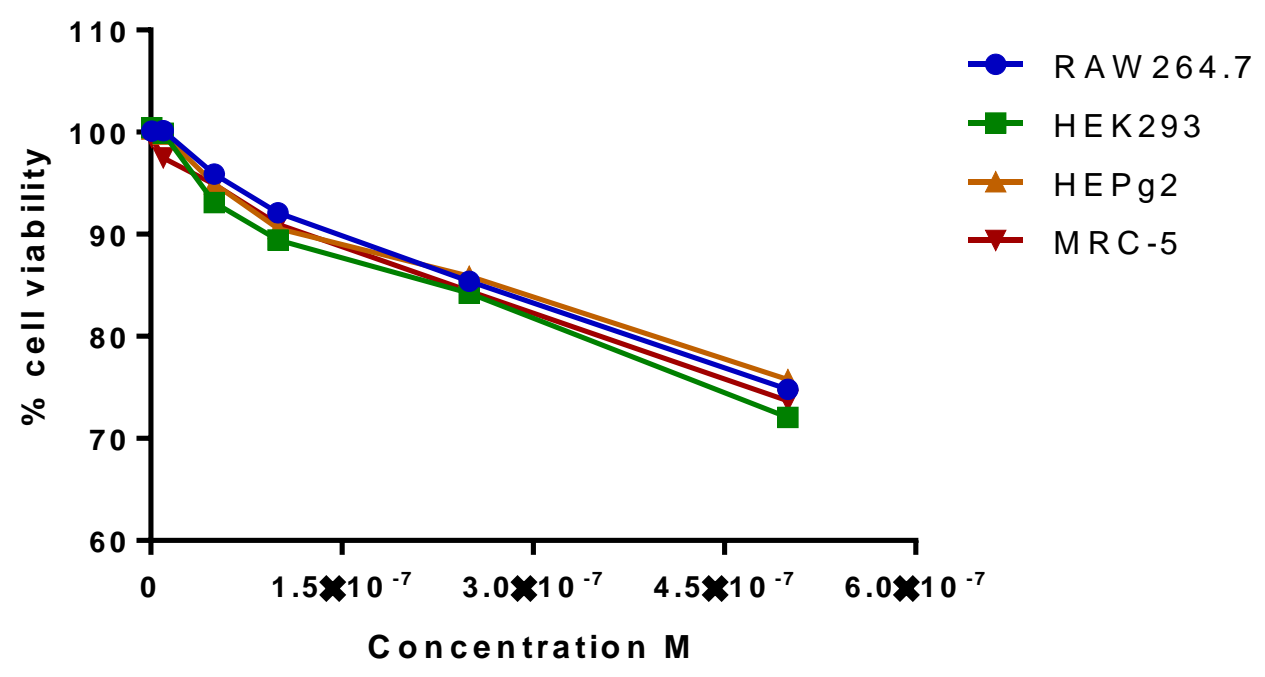

In vitro

$\pm$ 
Additionally, the uptake and internalization experiments performed in vitro for NIR-PSMAQDot incubated the test article for only $1 \mathrm{~h}$, within which sufficient receptor-mediated uptake was observed as fluorescence of QDot inside the cells. These experiments show that incubation of PSMA-NIR-QDot till $12 \mathrm{~h}$ is possible, without any toxic effects to cells.

\section{PSMA-NIR-QDot penetration and distribution in vitro in PCa 3D spheroid model}

Multicellular tumour spheroids, one of the most widely used three-dimensional (3D) culture systems, are proven to have many advantages over 2D culture for cancer research because they resemble many aspects of the pathophysiological conditions within human tumour tissue. We therefore developed spheroids of LNCaP PCa cells as an ex vivo tumour model using microwell method to generate large (dia $\sim 1.2 \mathrm{~mm}$ ), homogenous spheroids. Morphological analysis by confocal microscopy demonstrated that LNCaP cells formed tightly packed, rounded spheroids (figure 7). This is similar to in vivo tumour tissue, but different from monolayer cells. To further check the cell conditions in the tumour spheroids, LIVE/DEAD viability assay using fluorescein diacetate (FDA, stains live cells green) and Propidium Iodide (PI, stains dead cells red). The data indicated that cells in 2-day-cultured spheroids consisted of a majority of live cells (figure 7) of metabolically active cells. These cells mainly localized to the outer part of the spheroid. A smaller group of apoptotic cells, which stained weakly with PI red and were mainly found in the center of the spheroid. Two cell populations were also observed in 5-day-cultured spheroids, although the proportion of apoptotic cells increased as the culture time increased from 2 days to 5 days.

A multiphoton analysis study was performed to further analyze the cellular microstructure of the spheroids, and it confirmed that cells near the surface were in a healthy condition, similar to cells in monolayer culture, while the cells in the middle of the spheroid were apoptotic or injured and showed obvious chromatin compaction and segregation. These results suggested that multicellular tumour spheroids mimic the distribution of cells around blood vessels in tumour tissue in vivo. The outer region of the spheroid corresponds to tumour tissue near the blood supply, where cells proliferate in the presence of sufficient oxygen and nutrients. The inner region of the spheroid is quite similar to tumour tissue far away from the blood supply, where cells experience decreased oxygen and nutrients. 


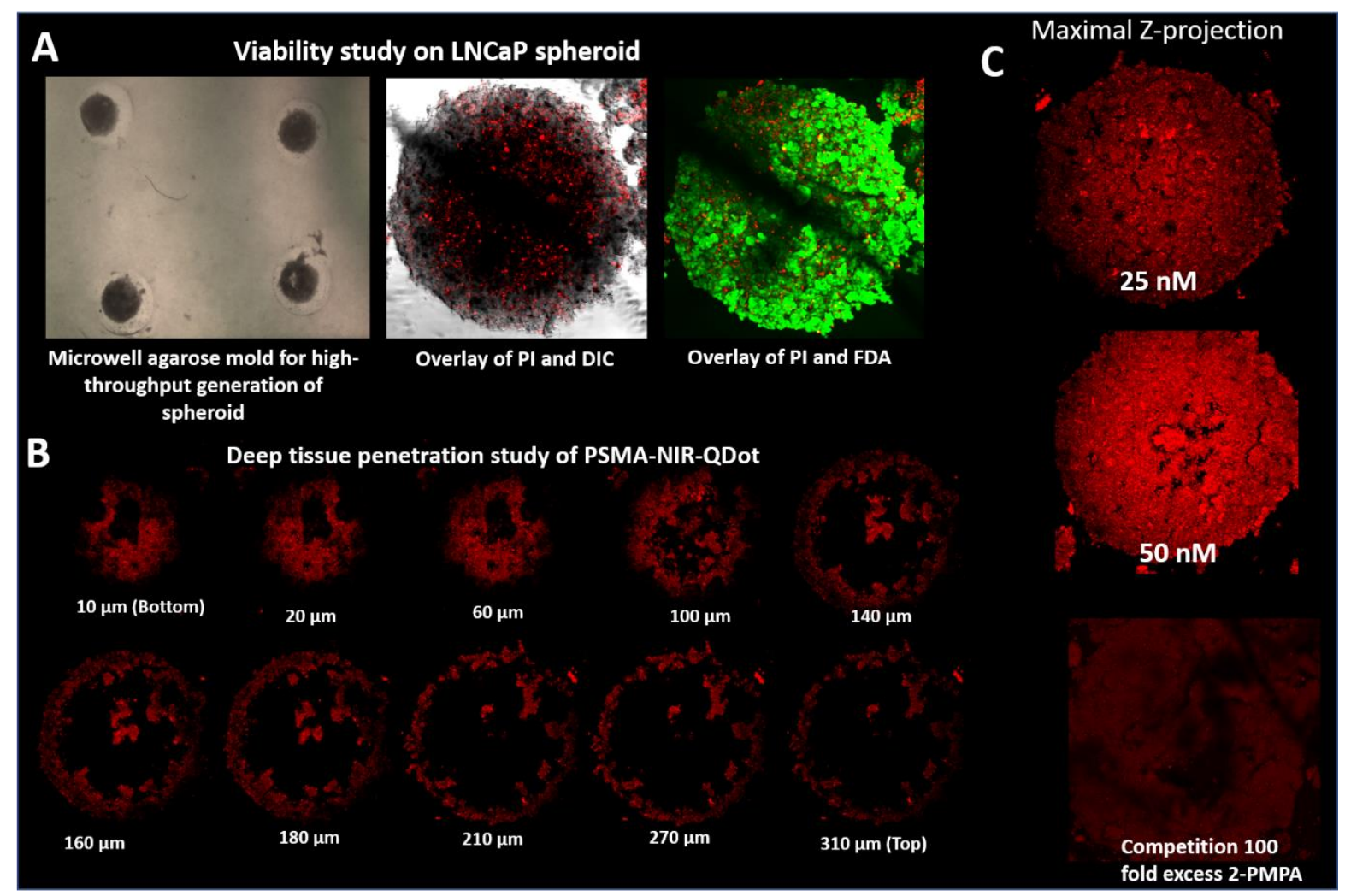

Figure 7: Penetration and localisation of PSMA-NIR-QDot in 3D LNCaP spheroids. (A) Formation of 2day spheroids by agarose microwell method, LIVE/DEAD viability assay using FDA/PI for characterisation of spheroid (B) Montage of penetration and distribution analysis of PSMA-NIR-QDot in PCa 3D tumour model. (C) Maximal Z-projection of LNCaP spheroid incubated with $25 \mathrm{nM}$ and $50 \mathrm{nM}$ of PSMA-NIR-QDot along with competition experiment with excess 2-PMPA.

There was no obvious difference in morphology of the spheroids after treatment with PSMANIR-QDot at $25 \mathrm{nM}$ and $50 \mathrm{nM}$, for 2 hours and 4 hours, as compared to untreated control spheroids (figure 7). Multiphoton imaging at $790 \mathrm{~nm}$ was carried out in order to confirm the exact site of localization of the PSMA-NIR-QDot in the spheroid. The nanoprobes can be seen to be distributed throughout the optical cross-section of the spheroid, deep inside the tumour model core (figure 7B, $140 \mu \mathrm{m}$ slice). As per literature reports, rarely have nanoprobes penetrated completely inside the spheroid tissue, presumably due to larger size and non-targeted nature. PSMA-NIR-QDot however, has shown complete distribution throughout the tissue, the penetration enabled by high-affinity PSMA binding DUPA ligand. PSMA receptors were blocked by incubating the spheroid in 100-fold excess PMPA for $4 \mathrm{hrs}$ prior to adding nanoprobe. The maximal z-section shows contrasting images for PSMA-NIRQdot accumulation inside spheroid and when receptors are blocked with 2-PMPA (figure 7C). This proves the specificity in detection of PCa cells when tumour malignancies grow next to primary tissues, enabling surgeons to identify PCa cells for effective tumour removal.

\section{Conclusion}


The objective of the study was to introduce a prostate cancer-specific NIR agent that could assist surgeons to conduct radical prostatectomies with negative tumor margins. Conventional prognostic modalities such as visual inspection and palpation may lead to BCR as a result of incomplete tumor removal or to erectile dysfunction and/or urinary incontinence due to nerve damages. Thus, we developed a PSMA-targeted NIR-Qdot that: (i) binds to PSMA ${ }^{+}$tumors with high affinity and specificity; (ii) allows use of subnanomolar concentration to visualize small tumors; (iii) retains tumor fluorescence for over 48 hours, allowing visualization throughout FGS; (v) allows to accomplish negative surgical tumor margins; and (vi) has an excellent safety profile in primary cell lines. Moreover, PSMA-NIR-QDot can be readily synthesized in multigram quantities at low cost with high purity and excellent yield.

PSMA-NIR-Qdot imaging probes have a number of advantages over conventional imaging probes used for deep tissue imaging (i) exceptionally bright, stable signal for clear, extended visualisation due to high quantum yield of QDots, (ii) red-shifted emission wavelengths for increased tissue penetration, (iii) excitation from a single wavelength for multiplexing capacities in biological systems.

Although tumour-specific NIR dyes have not yet entered the clinic for use in radical prostatectomy, several PSMA-targeted NIR dyes are currently under preclinical development. Unfortunately, antibody-targeted dyes such as J591-ICG have taken $\sim 2$ days to obtain acceptable tumour contrast in PSMA-transfected prostate cancer tumour xenograft model. The observed slow clearance from the non-malignant tissues and longer optimal imaging time necessitate a prolonged hospital stay or multiple hospital visits, leading to higher cumulative cost. Due to its high affinity and specificity for PSMA-expressing tumors, rapid clearance from PSMA-negative healthy tissues, excellent safety profile, and amenability to synthesize in gram scale at low cost, PSMA-NIR-QDot has proven to be a clinical candidate to yield sharp tumor boundaries with negative tumor margins within 1 to 2 hours of infusion in the 3D PCa model. With its recent entry into deep-tissue imaging, PSMA-NIR-Qdot has the potential to become the first PSMA-targeted NIR agent to enter into the clinic for use in fluorescenceguided radical prostatectomy.

Because the most reliable treatment strategy for $\mathrm{PCa}$ involves quantitative resection of all cancerous tissues, considerable effort has been devoted to improving a surgeon's ability to locate and remove all malignant lesions. With the advent of improved optical imaging technology, we have focused on developing PCa targeted NIR nanoprobes to selectively illuminate cancer nodules during surgery. We have successfully designed, developed and evaluated the optical properties, in vitro monolayer and 3D tumor specificity/affinity, pharmacokinetics, preclinical toxicology, and some clinical application of a PSMA receptortargeted NIR-QDot (PSMA-NIR-QDot) that concentrates specifically in cancer tissues. Thus, when used in combination with an NIR illumination technology, PSMA-NIR-QDot constitutes an excellent tumor-specific optical imaging agent that can enable surgeons to locate and resect more cancer tissue and thereby prolong patient survival. 


\section{AUTHOR INFORMATION}

Mena Asha Krishnan, email: phd1401171003@iiti.ac.in; Venkatesh Chelvam, cvenkat@iiti.ac.in, Paul Roach, p.roach@lboro.ac.uk

\section{Corresponding Authors}

Venkatesh Chelvam, cvenkat@iiti.ac.in; Paul Roach, p.roach@lboro.ac.uk

\section{Author Contributions}

Mena Asha Krishnan (MAK) performed the synthesis, biological evaluation of NIR-PSMAQDot and drafted the initial manuscript. Venkatesh Chelvam ideated the research, guided and executed the project for biological evaluation and future applications along with correcting the draft and revising the final manuscript critically for important intellectual content. Paul Roach contributed in terms of laboratory set-up during secondment and helping to revise manuscript. All authors have given approval to the final version of the manuscript.

\section{Funding Sources}

Ministry of Human Resource Development (MHRD), Government of India and Indian Institute of Technology (IIT) Indore, India for research funding and student's research fellowships.

\section{ACKNOWLEDGMENT}

The authors are thankful to Ministry of Human Resource Development (MHRD), Government of India and Indian Institute of Technology (IIT) Indore, India, Newton-Bhabha Research Fellowship, Keele university (where secondment took place) and British Council for research funding and student's research fellowships. We also thank Sophisticated Instrumentation Centre (SIC), IIT Indore for facilitating the use of their instruments required for purification and characterization of our bioconjugate and for helping in performing the two-photon laser scanning analysis, z-scanning analysis and confocal microscopy.

\section{ABBREVIATIONS}

PCa, Prostate Cancer; PSMA, Prostate Specific Membrane Antigen; TLC, thin layer chromatography.

\section{Bibliography}

(1) Siegel, R. L.; Miller, K. D.; Jemal, A. Cancer Statistics, 2019. CA. Cancer J. Clin. 2019, 69 (1), 7-34. https://doi.org/10.3322/caac.21551.

(2) Ankerst, D. P.; Miyamoto, R.; Nair, P. V.; Pollock, B. H.; Thompson, I. M.; Parekh, D. J. Yearly Prostate Specific Antigen and Digital Rectal Examination Fluctuations in a 
Screened Population. J. Urol. 2009, 181 (5), 2071-2076.

https://doi.org/10.1016/j.juro.2009.01.029.

(3) Mansbridge, M.; Chung, E.; Rhee, H. The Use of MRI and PET Imaging Studies for Prostate Cancer Management: Brief Update, Clinical Recommendations, and Technological Limitations. Med. Sci. 2019, 7 (8), 85.

https://doi.org/10.3390/medsci7080085.

(4) Sarkar, S.; Das, S. A Review of Imaging Methods for Prostate Cancer Detection. Biomed. Eng. Comput. Biol. 2016, 7s1, BECB.S34255. https://doi.org/10.4137/becb.s34255.

(5) Borley, N.; Feneley, M. R. Prostate Cancer: Diagnosis and Staging. Asian J. Androl. 2009, 11 (1), 74-80. https://doi.org/10.1038/aja.2008.19.

(6) Matthew R. Cooperberg, , Andrew J. Vickers, Jeanette M. Broering, Peter R. Carroll, and the C. I. Comparative Risk-Adjusted Mortality Outcomes Following Primary Surgery, Radiation Therapy, or Androgen Deprivation Therapy for Localized Prostate Cancer. Cancer 2010, 116 (22), 5226-5234. https://doi.org/10.1038/jid.2014.371.

(7) Abdollah, F.; Sun, M.; Schmitges, J.; Tian, Z.; Jeldres, C.; Briganti, A.; Shariat, S. F.; Perrotte, P.; Montorsi, F.; Karakiewicz, P. I. Cancer-Specific and Other-Cause Mortality After Radical Prostatectomy Versus Observation in Patients with Prostate Cancer: Competing-Risks Analysis of a Large North American Population-Based Cohort. Eur. Urol. 2011, 60 (5), 920-930. https://doi.org/10.1016/j.eururo.2011.06.039.

(8) Wieder, J. A.; Soloway, M. S. Incidence, Etiology, Location, Prevention and Treatment of Positive Surgical Margins after Radical Prostatectomy for Prostate Cancer. J. Urol. 1998, 160 (2), 299-315. https://doi.org/10.1016/S00225347(01)62881-7.

(9) Freedland, S. J.; Presti, J. C.; Amling, C. L.; Kane, C. J.; Aronson, W. J.; Dorey, F.; Terris, M. K. Time Trends in Biochemical Recurrence After Radical Prostatectomy: Results of the SEARCH Database. Urology 2003, 61 (4), 736-741. https://doi.org/10.1016/S0090-4295(02)02526-8.

(10) Jonathan DeLong; Hoffman; Bouvet, M. Current Status and Future Perspectives of Fluorescence-Guided Surgery for Cancer. Expert Rev Anticancer Ther. 2017, 176 (1), 139-148. https://doi.org/10.1016/j.physbeh.2017.03.040.

(11) Nguyen, Q. T.; Roger Y. Tsien. Fluorescence-Guided Surgery with Live Molecular Navigation - a New Cutting Edge. Physiol. Behav. 2017, 176 (1), 139-148. https://doi.org/10.1016/j.physbeh.2017.03.040.

(12) Silver, D. A.; Pellicer, I.; Fair, W. R.; Heston, W. D.; Cordon-Cardo, C. ProstateSpecific Membrane Antigen Expression in Normal and Malignant Human Tissues. Clin. Cancer Res. 1997, 3 (1), 81-85.

(13) Bostwick, D. G.; Pacelli, A.; Blute, M.; Roche, P.; Ph, D.; Murphy, G. P. Prostate Specific Membrane Antigen Expression in Prostatic Intraepithelial Neoplasia and Adenocarcinoma A Study of 184 Cases. Cancer 1998, 2256-2261.

(14) Ghosh, A.; Heston, W. D. W. Tumor Target Prostate Specific Membrane Antigen (PSMA) and Its Regulation in Prostate Cancer. J. Cell. Biochem. 2004, 91 (3), 528 539. https://doi.org/10.1002/jcb.10661.

(15) Rajasekaran, S. A.; Gopalakrishnapillai, A.; Oshima, E.; Bowie, J.; Liu, H.; Heston, 
W. D. W.; Bander, N.; Rajasekaran, A. A Novel Cytoplasmic Tail MXXXL Motif Mediates the Internalization of Prostate-Specific Membrane Antigen. Mol. Biol. Cell 2003, 14, 4835-4845. https://doi.org/10.1091/mbc.E02.

(16) Roy, J.; Nguyen, T. X.; Kanduluru, A. K.; Venkatesh, C.; Lv, W.; Reddy, P. V. N.; Low, P. S.; Cushman, M. DUPA Conjugation of a Cytotoxic Indenoisoquinoline Topoisomerase i Inhibitor for Selective Prostate Cancer Cell Targeting. J. Med. Chem. 2015, 58 (7), 3094-3103. https://doi.org/10.1021/jm5018384.

(17) Kozikowski, A. P.; Nan, F.; Conti, P.; Zhang, J.; Ramadan, E.; Bzdega, T.; Wroblewska, B.; Neale, J. H.; Pshenichkin, S.; Wroblewski, J. T. Design of Remarkably Simple, Yet Potent Urea-Based Inhibitors of Glutamate Carboxypeptidase II (NAALADase). J. Med. Chem. 2001, 44 (3), 298-301. https://doi.org/10.1021/jm000406m.

(18) Peng, Z.-H.; Sima, M.; Salama, M. E.; Kopeckova, P.; Kopecek, J. Spacer Length Impacts the Efficacy of Targeted Docetaxel Conjugates in Prostate-Specific Membrane Antigen Expressing Prostate Cancer. J Drug Target. 2013, 21 (10), 968-980. https://doi.org/10.1016/j.physbeh.2017.03.040.

(19) Wu, J. B.; Lin, T. P.; Gallagher, J. D.; Kushal, S.; Chung, L. W. K.; Zhau, H. E.; Olenyuk, B. Z.; Shih, J. C. Monoamine Oxidase a Inhibitor-near-Infrared Dye Conjugate Reduces Prostate Tumor Growth. J. Am. Chem. Soc. 2015, 137 (6), 23662374. https://doi.org/10.1021/ja512613j.

(20) Wester, H. J.; Schottelius, M. PSMA-Targeted Radiopharmaceuticals for Imaging and Therapy. Semin. Nucl. Med. 2019, 49 (4), 302-312. https://doi.org/10.1053/j.semnuclmed.2019.02.008.

(21) Schottelius, M.; Wirtz, M.; Eiber, M.; Maurer, T.; Wester, H. J. [111In]PSMA-I\&T: Expanding the Spectrum of PSMA-I\&T Applications towards SPECT and Radioguided Surgery. EJNMMI Res. 2015, 5 (1), 1-5. https://doi.org/10.1186/s13550015-0147-6.

(22) Knipper, S.; Tilki, D.; Mansholt, J.; Berliner, C.; Bernreuther, C.; Steuber, T.; Maurer, T.; Graefen, M. Metastases-Yield and Prostate-Specific Antigen Kinetics Following Salvage Lymph Node Dissection for Prostate Cancer: A Comparison Between Conventional Surgical Approach and Prostate-Specific Membrane AntigenRadioguided Surgery. Eur. Urol. Focus 2019, 5 (1), 50-53. https://doi.org/10.1016/j.euf.2018.09.014.

(23) Barrett, J. A.; Coleman, R. E.; Goldsmith, S. J.; Vallabhajosula, S.; Petry, N. A.; Cho, S.; Armor, T.; Stubbs, J. B.; Maresca, K. P.; Stabin, M. G.; et al. First-in-Man Evaluation of 2 High-Affinity PSMA-Avid Small Molecules for Imaging Prostate Cancer. J. Nucl. Med. 2013, 54 (3), 380-387. https://doi.org/10.2967/jnumed.112.111203.

(24) Chakravarty, R.; Siamof, C. M.; Dash, A.; Cai, W. Targeted $\alpha$-Therapy of Prostate Cancer Using Radiolabeled PSMA Inhibitors: A Game Changer in Nuclear Medicine. Am. J. Nucl. Med. Mol. Imaging 2018, 8 (4), 247-267.

(25) Derks, Y. H. W.; Löwik, D. W. P. M.; Sedelaar, J. P. M.; Gotthardt, M.; Boerman, O. C.; Rijpkema, M.; Lütje, S.; Heskamp, S. PSMA-Targeting Agents for Radio- and Fluorescence- Guided Prostate Cancer Surgery. Theranostics 2019, 9 (23), 6824-6839. https://doi.org/10.7150/thno.36739.

(26) Humblet, V.; Lapidus, R.; Williams, L. R.; Tsukamoto, T.; Rojas, C.; Majer, P.; Hin, 
B.; Ohnishi, S.; De Grand, A. M.; Zaheer, A.; et al. High-Affinity Near-Infrared Fluorescent Small-Molecule Contrast Agents For In Vivo Imaging of Prostate-Specific Membrane Antigen. Mol. Imaging 2005, 4 (4), 448-462.

(27) Xinning Wang, Steve S. Huang, Warren D.W. Heston, Hong Guo, Bing-Cheng Wang, and J. P. B. Development of Targeted Near-Infrared Imaging Agents for Prostate Cancer. Mol Cancer Ther 2014, 13 (11), 2595-2606. https://doi.org/10.1016/j.physbeh.2017.03.040.

(28) Kelderhouse, L. E.; Chelvam, V.; Wayua, C.; Mahalingam, S.; Poh, S.; Kularatne, S. A.; Low, P. S. Development of Tumor-Targeted Near Infrared Probes for Fluorescence Guided Surgery. Bioconjug. Chem. 2013, 24 (6), 1075-1080. https://doi.org/10.1021/bc400131a.

(29) Vahrmeijer, A. L.; Hutteman, M.; Vorst, J. R.; Velde, C. J. H.; Frangioni, J. V. ImageGuided Cancer Surgery Using Near-Infrared Fluorescence. Nat Rev Clin Oncol. 2014, 10 (9), 507-518. https://doi.org/10.1038/nrclinonc.2013.123.Image-guided.

(30) Fomina, N.; McFearin, C. L.; Sermsakdi, M.; Morachis, J. M.; Almutairi, A. Low Power, Biologically Benign NIR Light Triggers Polymer Disassembly. Macromolecules. 2011, 44 (21), 8590-8597. https://doi.org/10.1038/jid.2014.371.

(31) Larson, D. R.; Zipfel, W. R.; Williams, R. M.; Clark, S. W.; Bruchez, M. P.; Wise, F. W.; Webb, W. W. Water-Soluble Quantum Dots for Multiphoton Fluorescence Imaging in Vivo. Science (80-. ). 2003, 300 (5624), 1434-1436. https://doi.org/10.1126/science.1083780.

(32) Rosenthal, S. J.; Tomlinson, I.; Adkins, E. M.; Schroeter, S.; Adams, S.; Swafford, L.; McBride, J.; Wang, Y.; DeFelice, L. J.; Blakely, R. D. Targeting Cell Surface Receptors with Ligand-Conjugated Nanocrystals. J. Am. Chem. Soc. 2002, 124 (17), 4586-4594. https://doi.org/10.1021/ja003486s.

(33) Alivisatos, A. P. Semiconductor Clusters, Nanocrystals, and Quantum Dots. Science (80-. ). 1996, 271, 933-936.

(34) Gao, X.; Cui, Y.; Levenson, R. M.; Chung, L. W. K.; Nie, S. In Vivo Cancer Targeting and Imaging with Semiconductor Quantum Dots. Nat. Biotechnol. 2004, 22 (8), 969976. https://doi.org/10.1038/nbt994.

(35) Wu, X.; Liu, H.; Liu, J.; Haley, K. N.; Treadway, J. A.; Larson, J. P.; Ge, N.; Peale, F.; Bruchez, M. P. Immunofluorescent Labeling of Cancer Marker Her2 and Other Cellular Targets With Semiconductor Quantum Dots. Nat. Biotechnol. 2003, 21 (1), 41-46. https://doi.org/10.1038/nbt764.

(36) Jaiswal, J. K.; Mattoussi, H.; Mauro, J. M.; Simon, S. M. Long-Term Multiple Color Imaging of Live Cells Using Quantum Dot Bioconjugates. Nat. Biotechnol. 2003, 21 (1), 47-51. https://doi.org/10.1038/nbt767.

(37) Medintz, I. L.; Konnert, J. H.; Clapp, A. R.; Stanish, I.; Twigg, M. E.; Mattoussi, H.; Mauro, J. M.; Deschamps, J. R. A Fluorescence Resonance Energy Transfer-Derived Structure of a Quantum Dot-Protein Bioconjugate Nanoassembly. Proc. Natl. Acad. Sci. U. S. A. 2004, 101 (26), 9612-9617. https://doi.org/10.1073/pnas.0403343101.

(38) Mammen, M.; Choi, S. K.; Whitesides, G. M. Polyvalent Interactions in Biological Systems: Implications For Design and Use of Multivalent Ligands and Inhibitors. Angew. Chemie - Int. Ed. 1998, 37 (20), 2754-2794. https://doi.org/10.1002/(sici)1521-3773(19981102)37:20<2754::aidanie2754>3.0.co;2-3. 
(39) Sengupta, S.; Krishnan, M. A.; Dudhe, P.; Reddy, R. B.; Giri, B.; Chattopadhyay, S.; Chelvam, V. Novel Solid-Phase Strategy for the Synthesis of Ligand-Targeted Fluorescent-Labelled Chelating Peptide Conjugates as a Theranostic Tool for Cancer. Beilstein J. Org. Chem. 2018, 14, 2665-2679. https://doi.org/10.3762/bjoc.14.244.

(40) Sengupta, S.; Krishnan, M. A.; Pandit, A.; Dudhe, P.; Sharma, R.; Chelvam, V. Tyrosine-Based Asymmetric Urea Ligand for Prostate Carcinoma: Tuning Biological Efficacy through in Silico Studies. Bioorg. Chem. 2019, 91 (July), 103154. https://doi.org/10.1016/j.bioorg.2019.103154.

(41) Kularatne, S. A.; Zhou, Z.; Yang, J.; Post, C. B.; Low, P. S. Design, Synthesis, and Preclinical Evaluation of Prostate-Specific Membrane Antigen Targeted (99m)TcRadioimaging Agents. Mol. Pharm. 2009, 6 (3), 790-800. https://doi.org/10.1021/mp9000712.

(42) Zhu, Y.; Hong, H.; Xu, Z.; Li, Z.; Cai, W. Quantum Dot-Based Nanoprobes for In Vivo Targeted Imaging. Curr. Mol. Med. 2013, 13 (10), 1549-1567. https://doi.org/10.2174/1566524013666131111121733.

(43) Sperling, R. A.; Parak, W. J. Surface Modification, Functionalization and Bioconjugation of Colloidal Inorganic Nanoparticles. Philos. Trans. R. Soc. A Math. Phys. Eng. Sci. 2010, 368 (1915), 1333-1383. https://doi.org/10.1098/rsta.2009.0273.

(44) Cai, W.; Chen, X. Preparation of Peptide-Conjugated Quantum Dots for Tumor Vasculature-Targeted Imaging. Nat. Protoc. 2008, 3 (1), 89-96. https://doi.org/10.1038/nprot.2007.478.

(45) Banerjee, A.; Grazon, C.; Nadal, B.; Pons, T.; Krishnan, Y.; Dubertret, B. Fast, Efficient, and Stable Conjugation of Multiple DNA Strands on Colloidal Quantum Dots. Bioconjug. Chem. 2015, 26, 1582-1589.

https://doi.org/10.1021/acs.bioconjchem.5b00221. 